\title{
International Market Entry Strategies: Relational, Digital, and Hybrid Approaches
}

\author{
George F. Watson IV, Scott Weaven, Helen Perkins, Deepak Sardana, and \\ Robert W. Palmatier
}

\begin{abstract}
The adoption of digital communications, facilitated by Internet technology, has been among the most significant international business developments of the past 25 years. This article investigates the effect of these new technologies and the changing global business environment to understand how relational approaches to international market entry (IME) are changing in light of macro developments. Despite substantial resources in business practice dedicated to combining relational strategies in digital settings, this analysis of extant literature reveals that fewer than 3\% of peer-reviewed research articles in the international marketing domain examine digital contexts. To address this gap, the authors assess 25 years of literature to provide (1) a description of the evolution of IME research; (2) a review and synthesis of pertinent literature that adopts relational, digital, and bybrid approaches to IME; (3) a taxonomy of IME strategies; and (4) directions for further research.
\end{abstract}

Keywords: international market entry, relationship marketing, digital marketing, hybrid strategies

$\mathrm{M}$ odern digital communications, facilitated by Internet technology (IT), account for approximately $22 \%$ of global economic output (Manyika et al. 2016). Advances in communications, logistics, and IT-combined with shrinking economic distances among nations, cross-border economic integration, and convergence in customer tastes and preferences-have fundamentally altered firms' ability to identify and sell to customers in international markets (Brun, Durif, and Ricard 2014; Mathews et al. 2016). Reflecting the importance of these developments, among its research priorities, the Marketing Science Institute (2016) asks of researchers, "How will we reach the marketplace of the future?" Yet fewer than $3 \%$ of articles in our review of the international marketing (IM) domain examine this future and its digital contexts, even as

George F. Watson IV is Assistant Professor of Marketing, Colorado State University (email: george.watson@colostate.edu). Scott Weaven is Professor of Marketing and Department Head (email: s.weaven@griffith. edu.au); Helen Perkins is Lecturer (email: h.perkins@griffith.edu.au); Deepak Sardana is Lecturer (email: d.sardana@griffith.edu.au), Department of Marketing, Griffith Business School, Gold Coast Campus, Griffith University. Robert W. Palmatier is Professor of Marketing, University of Washington (email: palmatrw@uw.edu). Bulent Menguc served as associate editor for this article. companies devote increasingly substantial resources to them. For example, companies offering digital customer relationship management (CRM) software grew their revenues by $12.3 \%$ to $\$ 26.3$ billion in 2015 (Poulter 2016). It remains unclear how these broader advances in digital and business environments affect international market entry (IME). In response, this article seeks to identify the effects of the changing global business environment on IME strategies and analyze the conditions that might influence the success or failure of different IME strategies (i.e., relational, digital, or hybrid).

Our discussion of the emergence of digital technologies in IME strategies tracks contemporary business developments and highlights the shortage of attention to the intersection of relational and digital approaches to IME. Of the 6,045 internationally oriented articles published in 29 prominent peer-reviewed marketing and business journals since 1994, approximately $60 \%$ contain relational topics. Such articles

Journal of International Marketing

(C2018, American Marketing Association

Vol. 26, No. 1, 2018, pp. 30-60

DOI: 10.1509/jim.17.0034

ISSN 1069-031X (print) 1547-7215 (electronic)

30 Journal of International Marketing 
also account for a little more than $60 \%$ of the total citations attributed to IM research in this period. Relatively few IM publications $(159$, or $3 \%)$ and citations $(2,776$, or $1 \%)$ out of the total work in international relationship-marketing research examine digital topics. In contrast, 1,004 domestic market articles, accruing 41,626 citations, examine hybrid (i.e., relational and digital simultaneously) topics across these same 29 journals in the same time period.

To inform this under-researched area, we begin with an assessment of the emergence of digital technologies in international relationship-marketing research to highlight its relative absence from contemporary academic thought. Next, we analyze the evolution of IME strategies, to provide a temporal overview of the effects of prior changes in global environments, as well as emerging IME approaches and contexts. In a third step, we review and synthesize literature pertaining to key relational, digital, and hybrid approaches by examining the legal, logistical, market, and cultural considerations for each; in so doing, we explicate some theoretical and empirical insights. Finally, we develop a taxonomy of IME approaches that reflects the combined use of relational and/or digital strategies, identified in our literature review and reflected in illustrative business case examples, to provide a framework for effective IME strategies. With the insights gained across these four perspectives, we delineate three major trends: the ubiquity of data-rich environments, marketing automation, and artificial intelligence. Each trend provides opportunities for impactful research due to its implications for firm learning and knowledge, as well as interorganizational trust and commitment.

In turn, we offer three main contributions. First, our review of relevant research into relational, digital, and hybrid approaches to IME provides a holistic overview of an underdeveloped domain. Digital interactions with channel partners and customers occur in substantially different environments than those described in traditional relationshipmarketing literature. In particular, hybrid approaches to IME require the adaptation of relational tactics to exploit new opportunities afforded by digital platforms. Interpersonal interactions may be missing, but Internet-mediated channels offer the unique benefits of convenience, speed, and even an ability to avoid salespeople entirely (Bhatnagar and Ghose 2004). In such environments, hybrid approaches need to address core relational issues such as trust, privacy, security, information sharing, bilateral communication, and shared learning, all in new ways (Creed, Zutshi, and Ross 2009). Rather than relying on person-to-person interactions or artificial boundary spanners, firms need to establish effective online relationship-building strategies with channel partners (Kozlenkova et al. 2017).
Second, our taxonomic classification of IME strategies helps define the domain of inquiry and identifies the conditions in which each approach is likely to be most effective. We provide a classification of various approaches (e.g., licensing, joint ventures, pure digital delivery), discuss likely determinants of their success or failure in each context, and offer illustrative cases to highlight key managerial considerations across distinct business environments. The value of relational approaches appears to increase with greater risk, particularly when the need arises to safeguard tangible firm assets (e.g., supply chains, distribution channels) and intangible customer assets (e.g., proprietary information, location data, usage behavior) in the face of novel legal, logistical, market, and cultural realities in a new foreign market. Success demands the appropriate adaptation of relational approaches in physical and digital contexts, especially as the rate of technological change accelerates and new technologies disrupt established practices.

Third, we offer directions for research, based on our assessment of extant literature and emerging practices in response to contemporary developments in IME practice. Considering the inherently uncertain environment of digitally mediated buyer-seller exchanges, new technologies that facilitate online relationship-marketing strategies can help mitigate cross-border market entry risks. Data-rich marketing environments, which are generally on the rise, feed into developments in marketing automation and artificial intelligence; yet despite their significant potential to alter relationship building in digital environments, they remain relatively understudied in IME literature.

\section{DIGITAL TECHNOLOGY AND INTERNATIONAL RELATIONSHIP MARKETING: KEYWORD ANALYSIS}

International relationship-marketing literature, and IM research more generally, consists of "thousands of publications that examine various aspects of the exchange between international buyers and sellers" (Samiee, Chabowski, and Hult 2015, p. 2). Considering the breadth of this literature, we propose using the keywords published with the articles as a good proxy for authors' collective sense of the past and present interests of the field (Mela, Roos, and Deng 2013). Analyses of these keywords, as well as citations of the articles in which they are contained, can reveal the share-of-mind for a particular subject or theme (Watson et al. 2015b). Extant citation-based analyses focus on marketing thought more generally (Baumgartner and Pieters 2003; Mela, Roos, and Deng 2013; Samiee and Chabowski 2012; Tellis, Chandy, and Ackerman 1999) or subdomains of the 
field, such as international relationship marketing and customer relationship management (Kevork and Vrechopoulos 2009; Samiee, Chabowski, and Hult 2015). To advance this research legacy, we investigate businessto-business (B2B) interorganizational contexts in particular. Rather than reproduce the overall knowledge structure of international relationship-marketing literature, we use these techniques to assess the extent to which digital themes have taken hold within academic research since the arrival of relationship marketing and IT.

Consistent with recent methodological best practices, we developed three lists of pertinent keywords to use in drawing data from the Web of Science (Chabowski, Mena, and Gonzalez-Padron 2011; Samiee and Chabowski 2012; Samiee, Chabowski, and Hult 2015). ${ }^{1}$ Within this database, we searched the publication title, abstract, author-provided keywords, and reference list for each article (Thomson Reuters 2009) 2 published in 29 management, marketing, and international business journals (Samiee and Chabowski 2012; Samiee, Chabowski, and Hult 2015). ${ }^{3}$ We eliminated from consideration book reviews, editorials, and other nonprimary research. The articles for potential inclusion were published after 1994, which is the year Morgan and Hunt's (1994) seminal article appeared and essentially founded relationship-marketing research (Palmatier et al. 2006). This date also marks the beginning of the "intermediate period" in international relationship-marketing literature (Samiee, Chabowski, and Hult 2015, p. 5) and is an early point in the widespread expansion of Internet communications (Elmer-Dewitt and Jackson 1994).

\footnotetext{
${ }^{1}$ Scholars summarize their work through their choice of title, abstract, and keywords to help other scholars determine whether their article is of interest. We use a broad list of keywords and follow recent studies employing similar methods (e.g., Samiee, Chabowski, and Hult 2015; Watson et al. $2015 \mathrm{~b}$ ) such that this approach should capture this literature stream well.

${ }^{2}$ The exact syntax for the search queries is available on request.

${ }^{3}$ The 29 journals were Academy of Management Review, Administrative Science Quarterly, British Journal of Management, California Management Review, (Columbia) Journal of World Business, Decision Sciences, European Journal of Marketing, Industrial Marketing Management, International Business Review, International Marketing Review, Journal of the Academy of Marketing Science, Journal of Business, Journal of Business \& Industrial Marketing, Journal of Business Research, Journal of International Business Studies, Journal of International Marketing, Journal of Management, Journal of Management Studies, Journal of Marketing, Journal of Marketing Research, Journal of Product Innovation Management, Journal of Public Policy \& Marketing, Journal of Retailing, Long Range Planning, Management International Review, Management Science, Marketing Science, Organization Science, and Strategic Management Journal.
}

With a comprehensive list of keywords, we sought to capture the full breadth of research across related domains, not just IME strategies. Therefore, we determined whether an article was international in nature (henceforth, category 1) by whether it contained keywords such as "international," "global," "foreign," "cross-national," "cross-cultural," "developed country," "developing country," “emerging country," "emerging market," "export," and "import” (Samiee and Chabowski 2012). Next, to discern whether an article focused on relationship marketing (category 2), we searched for keywords such as "relationship marketing," "governance," "dependence," "exchange," "inter-firm," "interdependence," "dyadic,” "buyer, “seller," “supplier,” “opportunism,” “cooperation," "trust," “commitment," “conflict," "power," "reciprocity," "norms," and "asset specificity” (Palmatier et al. 2006; Samiee, Chabowski, and Hult 2015). Finally, we investigated whether an article focused on digital contexts and topics (category 3), with search terms such as "digital," "internet," “online," "internet commerce," "cyberspace," “cyber-security," "world wide web," "web 2.0," "m-commerce," "mobile commerce," "e-commerce," "electronic commerce," "e-retailing," "mobile," "wireless," and "smartphone." By combining and excluding these three keyword lists using Boolean operators, we could determine whether a particular article published in the international domain across the 29 journals of interest was primarily relational (classified into categories 1 and 2 but not 3 ), primarily digital (classified into categories 1 and 3 but not 2), or hybrid (classified into all categories 1-3).

This search identified 6,045 articles that received 218,055 citations. Of these, 3,693 relational articles accounted for 133,723 citations; the 94 digital articles, 2,776 citations; and the 159 hybrid articles, 4,070 citations. Due to disparities in the number of published articles across categories, we chart the logged annual number of published articles attributed to these categories in Figure 1, to offer greater readability (Watson et al. 2015b).

In particular, the 3,693 relational articles account for more than $60 \%$ of international literature published over this more than 20 -year period, as well as more than $60 \%$ of the citations. In stark contrast, barely 3\% (159) of the publications and 1\% $(2,776)$ of total citations of international relationship-marketing research examine digital topics. For comparison, we note that 1,004 domestic (rather than international) articles, with 41,626 citations, examine hybrid topics (i.e., relational and digital simultaneously) across these 29 journals in the same period. Yet, as we noted previously, modern digital communications facilitated by IT account for approximately $22 \%$ of global economic output (Manyika et al. 2016), suggesting the substantial need for international relationship marketing to 
Figure 1. Article Count: International Marketing 1994-2016



Notes: Article count is based on 29 peer-reviewed business and marketing journals. For the complete list, see footnote 3 . Articles were counted if a keyword of interest based on previous literature (e.g., Samiee, Chabowski, and Hult 2015) appeared in the publication title, abstract, author-provided keywords, or article reference identifiers, available in the Thomson Reuters (2009) Web of Science Database. Category 1 (international): "international," "global," "foreign," "cross-national," "cross-cultural," "developed country," "developing country," "emerging country," "emerging market," “export," and "import." Category 2 (relationship marketing): "relationship marketing," "governance," "dependence," "exchange," "inter-firm," "interdependence," "dyadic," "buyer, "seller," "supplier," “opportunism,” "cooperation,” "trust," "commitment,” "conflict," "power," "reciprocity," "norms," and “asset specificity.” Category 3 (digital): “digital,” "internet," "online," "internet commerce,” "cyberspace," "cyber-security,” "world wide web," "web 2.0," "m-commerce," "mobile commerce," "e-commerce," "electronic commerce," "e-retailing," "mobile," "wireless," and "smartphone.” By combining and or excluding each of these three keyword lists with Boolean operators, we determined whether a particular article was primarily relational (categories 1 and 2 but not 3 ), primarily digital (categories 1 and 3 but not 2), or primarily hybrid (categories 1,2, and 3) within international research. Due to the large disparities in the sizes of these categories, we logged the article count by year, for enhanced readability.

devote more attention to these important topics. In particular, as digital markets cross physical borders, the importance of managing relationships across foreign contexts grows, especially in light of continued technological developments. To encourage such investigations, we detail the evolution of IME research next, then review pertinent literature that describes the legal, logistical, market, and cultural considerations firms might encounter when entering foreign markets. We base these analyses on our assessments of the content, works cited, and article lists contained in comprehensive reviews (Samiee and Chabowski 2012; Samiee, Chabowski, and Hult 2015), metaanalyses (Leonidou et al. 2014; Palmatier et al. 2006; Samaha, Beck, and Palmatier 2014), and well-cited articles related to each approach (Morgan and Hunt 1994).

\section{EVOLUTION OF IME STRATEGIES}

The past 30 years have witnessed significant shifts in IM research and practice, driven by increasing dynamism, global competitiveness, and altered international trade environments (Samiee, Chabowski, and Hult 2015). Most research takes a relational exchange perspective to examine the interactions between buyers and sellers in international contexts (Hoppner and Griffith 2015; Samiee, Chabowski, and Hult 2015), but historical views of IME strategies entail three major approaches, according to their level of relationalism: transactional, relational, or hybridized. Table 1 depicts the evolution of these IME approaches, in terms of key theories, trends, and insights. 


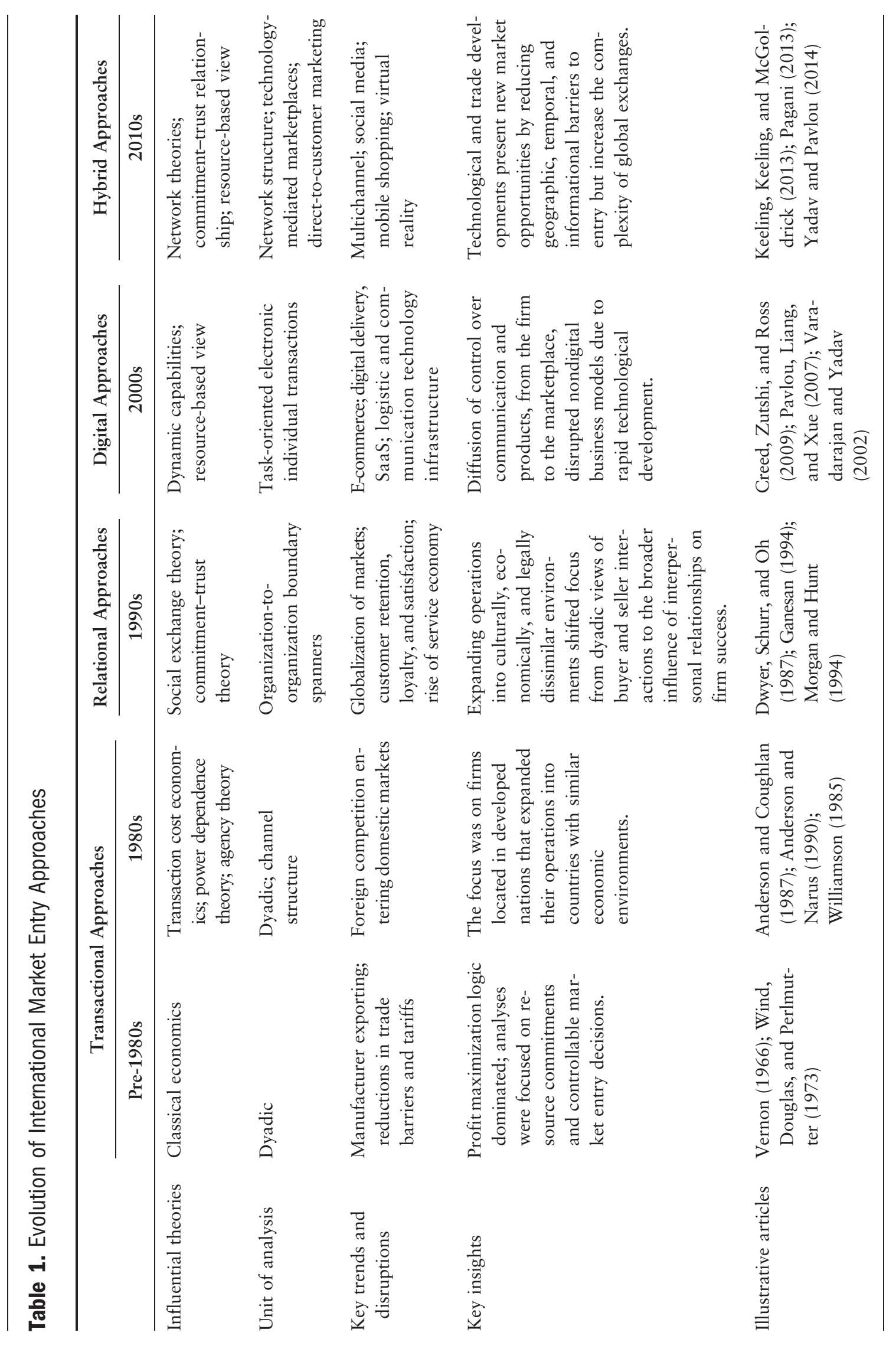

34 Journal of International Marketing 


\section{0s and Prior: Transactional Era}

Transactional IME approaches focus primarily on a set of profit-maximizing, risk-minimizing channel structure decisions (physical and/or digital) to deliver goods and services to an international market. Early IME research considered the increasing internationalization of business that accelerated in the late 1970s. Globalization came to the forefront of managerial concern; the notion of profit maximization, as derived from neo-classical economics, dominated academic thought, such that early IM literature mainly relied on transaction cost economics and related perspectives (e.g., Williamson 1985). The studies examined manufacturingdistributor exchanges, product life cycles, and managerial perceptions of IM, often in the context of foreign-market entry (Anderson and Narus 1990; Teece 1986). Accordingly, the focal points of interest in these early studies of dyadic buyer-seller exchanges involved resource commitments; controllable market-entry decisions; and the use of wholly owned subsidiaries, acquisitions, or equity stake holdings (Anderson and Coughlan 1987). Key concerns were the bounded rationality of managers, partner opportunism, monitoring (e.g., agency theory), and optimal governance choices, reflecting the less integrated international community. The perspective also strongly implied that firms in developed nations expanded their operations into culturally and economically comparable countries (Hoppner and Griffith 2015). However, such a focus on control and short-term exchanges attracted considerable criticism (Dwyer, Schurr, and Oh 1987), citing the deficiencies that arose from failing to account for relationalism in both domestic and international markets.

\section{0s: The Rise of Relationship Marketing}

In response to these criticisms, insights into relationship marketing joined the transaction cost arguments, with the idea that "the pursuit of caring associations and continuity" in business relationships was critical to effective IME (Samiee, Chabowski, and Hult 2015, p. 2). Relational IME approaches focus primarily on a set of strategies that seek to establish, maintain, and develop effective and mutually beneficial relationships between exchange partners (Leonidou et al. 2014; Skarmeas, Zeriti, and Baltas 2016; Zhuang and Zhang 2011). By the late 1980s, academic research entered an open debate about whether the field was experiencing a paradigm shift toward relationship marketing (Grönroos 1990), which exerted strong influences throughout the 1990s (Möller and Halinen 2000). Accordingly, IM research expanded to address the implications of employing a relationship-marketing lens to understand cross-border business. It also acknowledged that businesses located in developed nations were increasingly entering developing rather than developed economies; that is, they were expanding into culturally, economically, and legally dissimilar environments, in which local relationships proved immensely important for success (Hillman, Zardkoohi, and Bierman 1999; Samaha, Beck, and Palmatier 2014).

To safeguard tangible business investments in riskier foreign markets, having good relationships emerged as a critical factor (Jap and Ganesan 2000). Weak legal environments in developing economies complicated the kind of contract enforcement necessary for the transactional governance described by the transaction cost literature (Sheng, Zhou, and Li 2011). For example, foreign firms that sought to enter the Chinese domestic market were required to partner with a local, often government-owned enterprise (Faccio 2006), and the resulting transfer of proprietary intelligence and resources weakened firms' competitive advantage, by design (Nee, Opper, and Wong 2007). A more dyadic view of buyer-seller interactions also assisted in revealing the role of interpersonal relationships (Kogut and Singh 1988). Substantial research focused on the use of firm resources to encourage ongoing commitment and trust in marketing channel arrangements, such as strategic alliances and joint ventures (Calantone and Zhao 2001). The developments reflected the importance of the exchange in interfirm relationships, diverging from prior work on the singular firm's decisions as the unit of analysis (Achrol and Kotler 2012).

\section{0s to Present: The Merger of Digital and Relational Marketing}

Hybrid IME approaches focus on determining the appropriate mix of relational strategies employed within a channel structure that makes use of digital communication technologies to deliver the firm's product or service in a foreign market. Changes in global markets since the early 2000s, due to advances in information technology, domestic market saturation, and increasing competition in developing economies, have brought about a third wave in the development of IME approaches. Technological disruptions, in particular, have outsized impacts on firm behavior (Ashraf, Thongpapanl, and Auh 2014). Logistics and communication technology infrastructure enable firms to reach customers through task-oriented, human-to-technology transactions, though these channels often reduce levels of trust and loyalty (Keeling, Keeling, and McGoldrick 2013). Such changes also create new challenges, such as when they enable channel partners (e.g., intermediaries, manufacturers) to sell directly to customers through channel disintermediation and thereby increase levels of competition and the potential for conflict (Kozinets et al. 2010). 
Accordingly, many firms combine digital technologies and relational interactions in hybridized approaches to customer engagement to develop enduring customer involvement, trust, commitment, and loyalty toward online brands (Simmons 2008). Such hybrid approaches have naturally proven popular in markets with high Internet and mobile penetration (e.g., Japan, South Korea) but are also growing in use in the United States and other developed markets (Kim et al. 2011). As the price of smartphones continues to drop, these approaches are likely to continue expanding in middle- and lower-income economies as well (Saadi 2017). The continued drop in smartphone prices has enormous implications for hybrid approaches in lowerincome economies, in that it enables easy and frequent multichannel contacts, without requiring the purchase of relatively expensive computers to access the Internet. The potential for digital development is highest in Southeast Asia, Latin America, and parts of sub-Saharan Africa, due to their relatively low market saturation (Chakravorti, Tunnard, and Chaturvedi 2015).

Whether the approach is transactional, relational, or hybrid, IM clearly has evolved into what Brun, Durif, and Ricard (2014) call "e-relationship marketing." This form of marketing is key for realizing value in digital exchanges; it consists of integrated marketing communication facilitated by Internet-enabled technology platforms that engender trust, build commitment, improve satisfaction, and increase loyalty levels among exchange partners. However, poor applications can degrade relational outcomes (Jackson 2014), so navigating this shift to hybrid approaches to IME is not entirely straightforward.

\section{LITERATURE REVIEW: RELATIONAL, DIGITAL, AND HYBRID APPROACHES TO IME}

Despite the imbalance of literature, with far greater coverage of relational approaches to IME relative to digital or hybrid approaches, we provide assessments of extant literature pertaining to all three approaches (see Tables 2-4, respectively). For each approach, we highlight the key concepts and definitions, determinants of IME, and research findings. In this analysis, we also address four vital macroeconomic considerations with substantial influence on the success or failure of IME approaches (Dunning 2009): legal (Cavusgil, Deligonul, and Zhang 2004; Theodosiou and Katsikeas 2001), logistical (Bowersox and Calantone 1998; Douglas and Craig 2011), market (Anderson and Coughlan 1987; Cano, Carrillat, and Jaramillo 2004), and cultural (Samaha, Beck, and Palmatier 2014) considerations. In this sense, our focus in this section is on the external factors endemic to a foreign market "that are important determinants in the development of the firm's competitive advantage and its investment decisions" (Uddin and Boateng 2011, p. 548).

\section{Relational Approaches to IME}

Relational IME approaches primarily center on the set of strategies that seek to establish, maintain, and develop effective, mutually beneficial relationships among exchange partners (Leonidou et al. 2014; Zhuang and Zhang 2011). In particular, trust, defined as "confidence in an exchange partner's integrity and reliability" (Morgan and Hunt 1994, p. 23), and commitment, or the "enduring desire to maintain a valued relationship" (Moorman, Zaltman, and Deshpandé 1992, p. 316), are major determinants of exchange performance and lasting keystones of relationship marketing in international environments (Samiee, Chabowski, and Hult 2015).

Legal Considerations. In economies with stronger legal environments, firms can benefit from the careful use of contractual governance as a formal means to clarify channel member roles and expectations in new buyer-seller relationships to mitigate IME risk (Keeling, Keeling, and McGoldrick 2013). Contractual negotiation offers a conduit that enables goal sharing, dispute resolution, information exchange, explicit knowledge transfers, and management of expectations between parties, increasing the levels of transparency and accountability in the relationship (Griffith and Zhao 2015). In some contexts, however, formal contracts with specific requirements and extensive monitoring may signal mistrust, ignore the need for flexibility in the market, and undermine relationship efficacy, thereby encouraging (rather than discouraging) opportunism (Poppo and Zenger 2002; Zhuang and Zhang 2011). The successful implementation of relational approaches can address higher-risk environments by increasing the levels of customer trust, engagement, loyalty, and satisfaction (Brun, Durif, and Ricard 2014; Palmatier et al. 2006), particularly when weaker legal environments (as often characterize developing economies) complicate contract enforcement as a means to safeguard tangible assets, as anticipated by transaction cost economics (Sheng, Zhou, and Li 2011). Firms that adjust their contract specificity and formality to suit local legal characteristics and contractual norms, perhaps by adopting more relational governance methods (e.g., trust-enhancing strategies) and greater tolerance for minor contractual breaches, are more likely to achieve enhanced exchange performance in foreign markets (Yang, Su, and Fam 2012).

Logistical Considerations. Channel structures and information flows in new markets can influence the success of relational approaches to IME. For example, delays or 


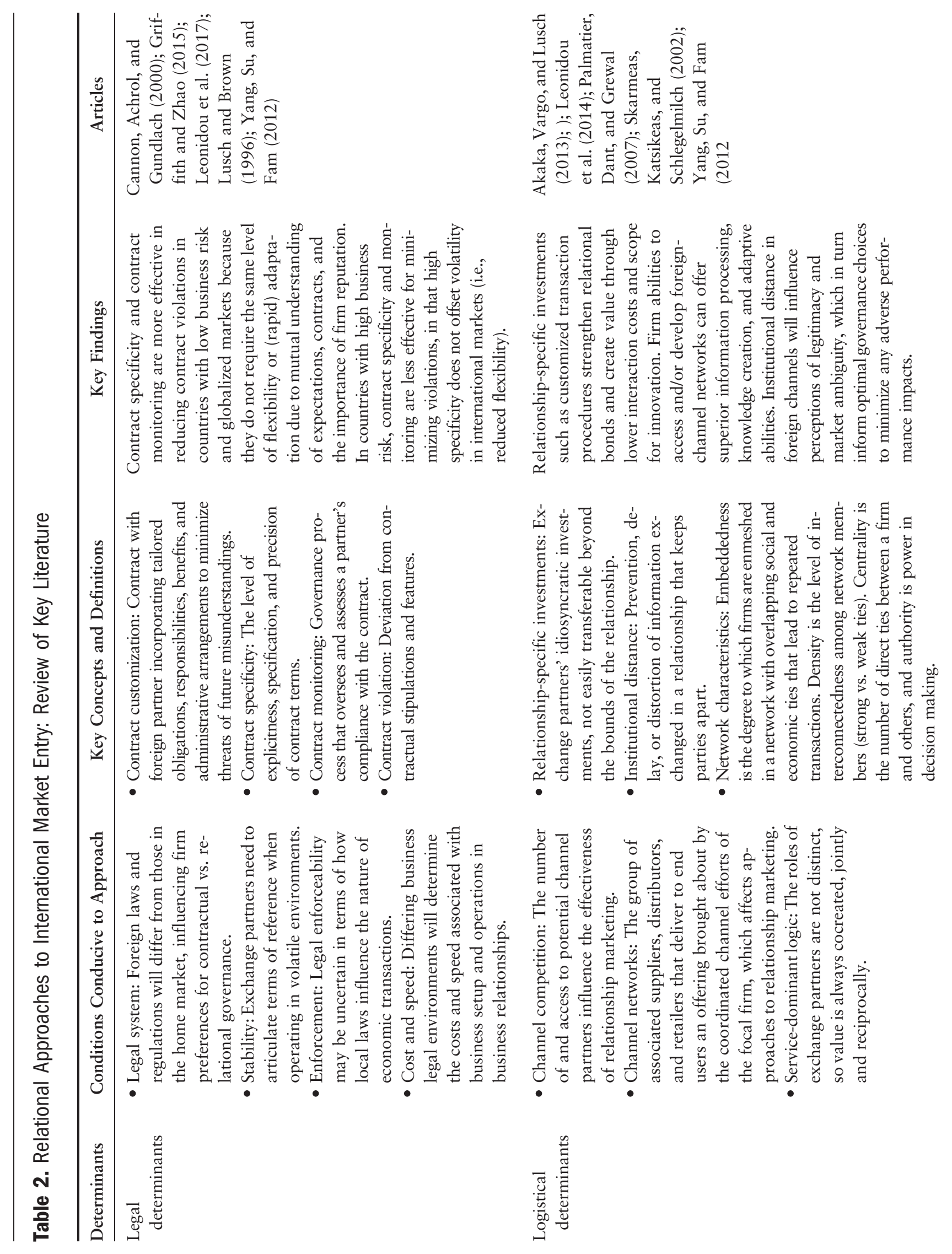




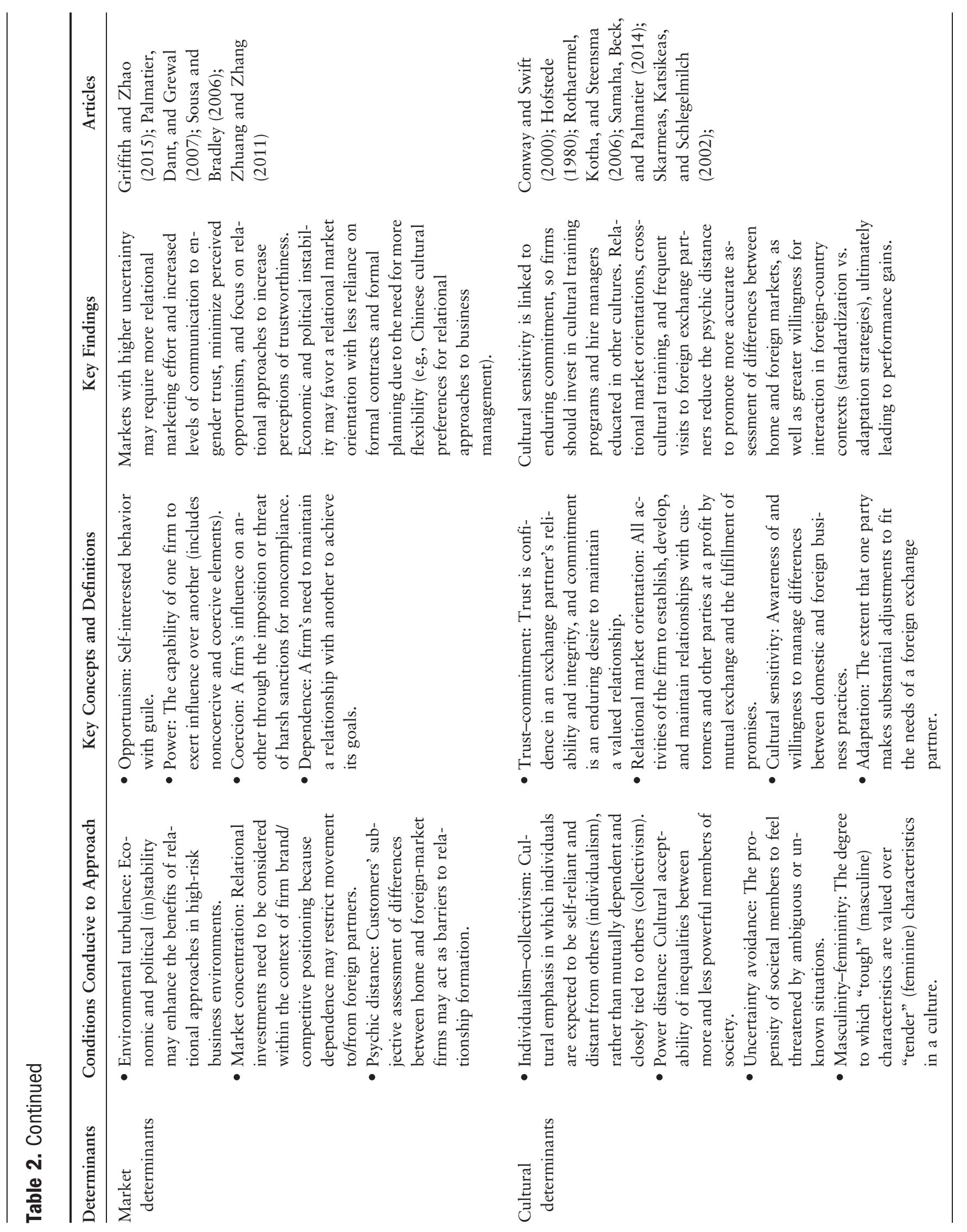

38 Journal of International Marketing 


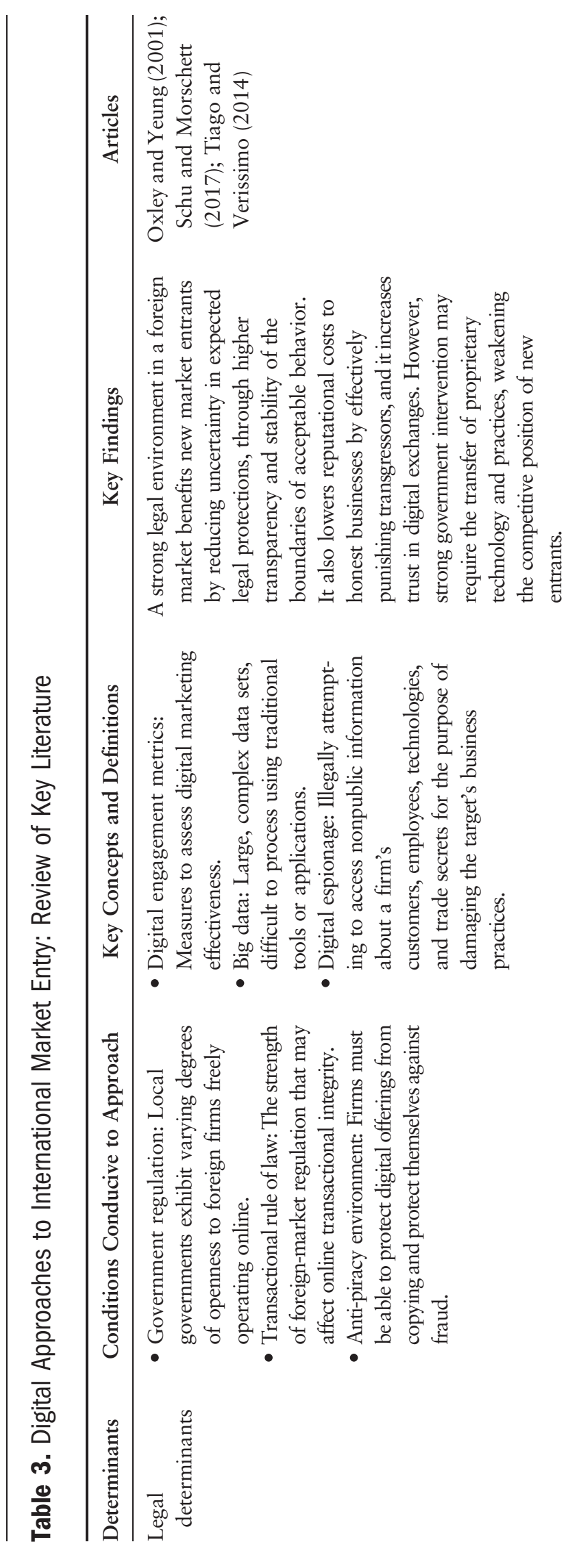

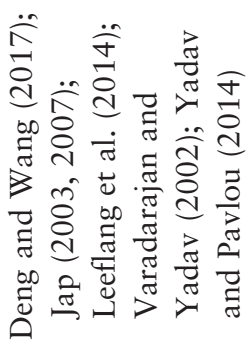
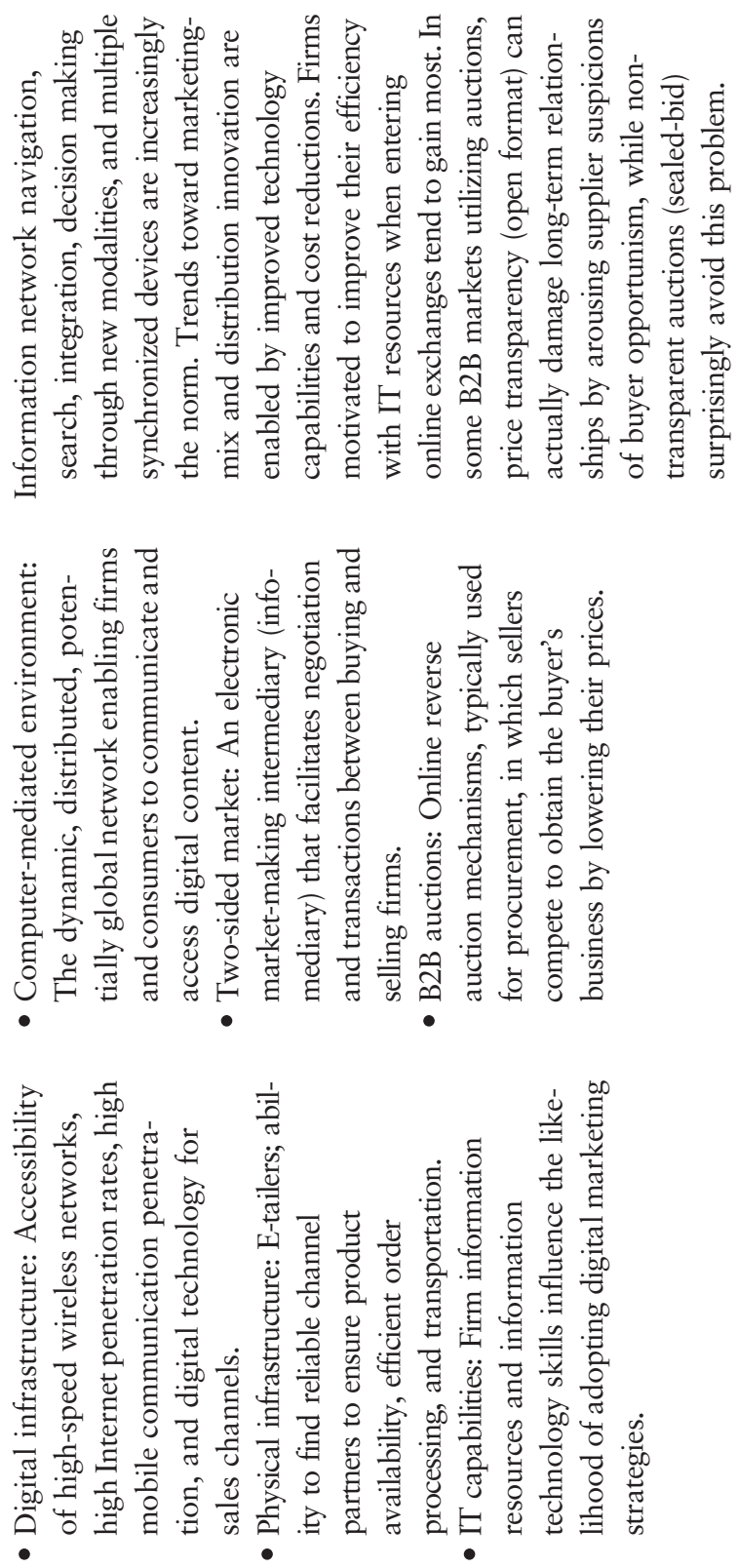


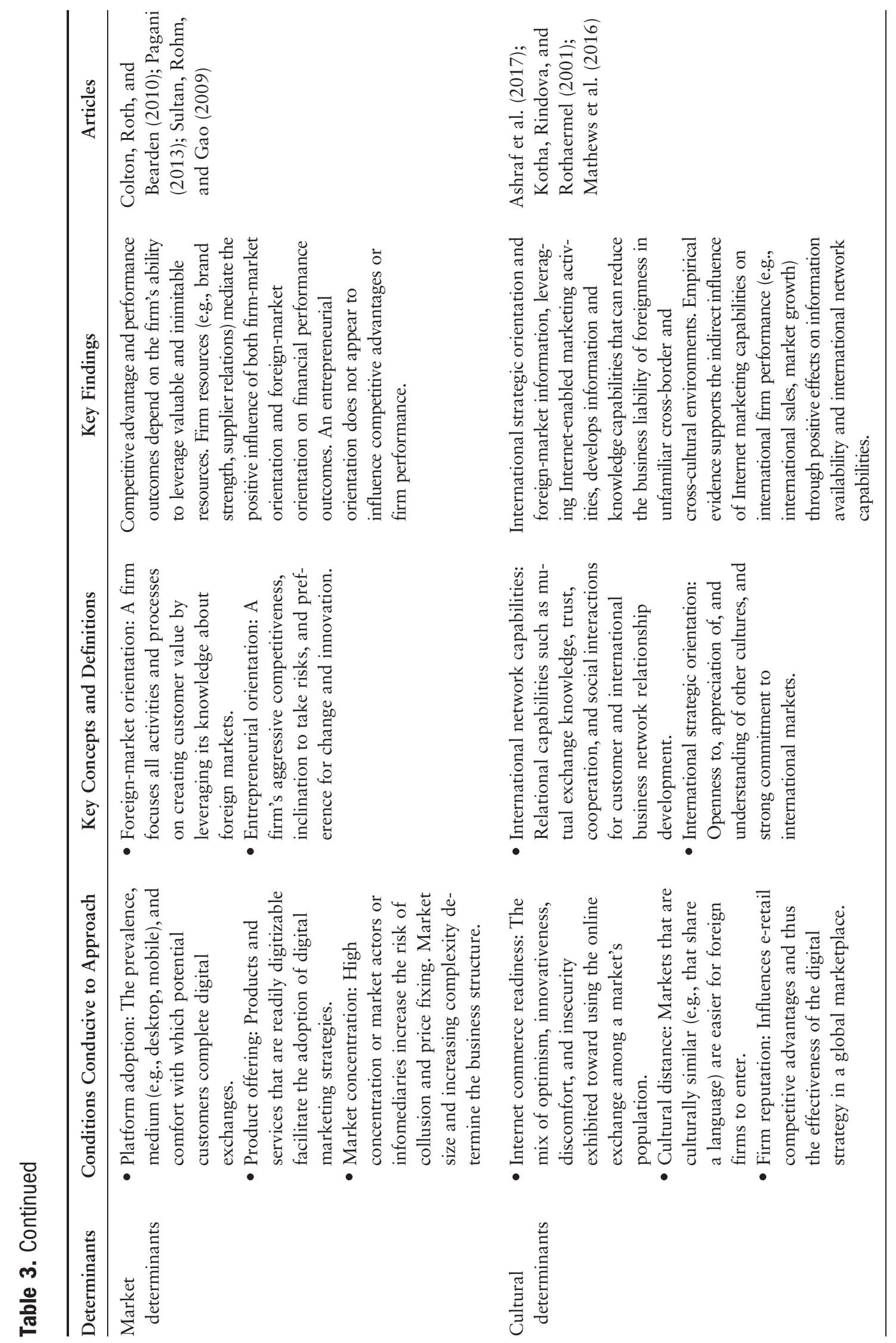

40 Journal of International Marketing 


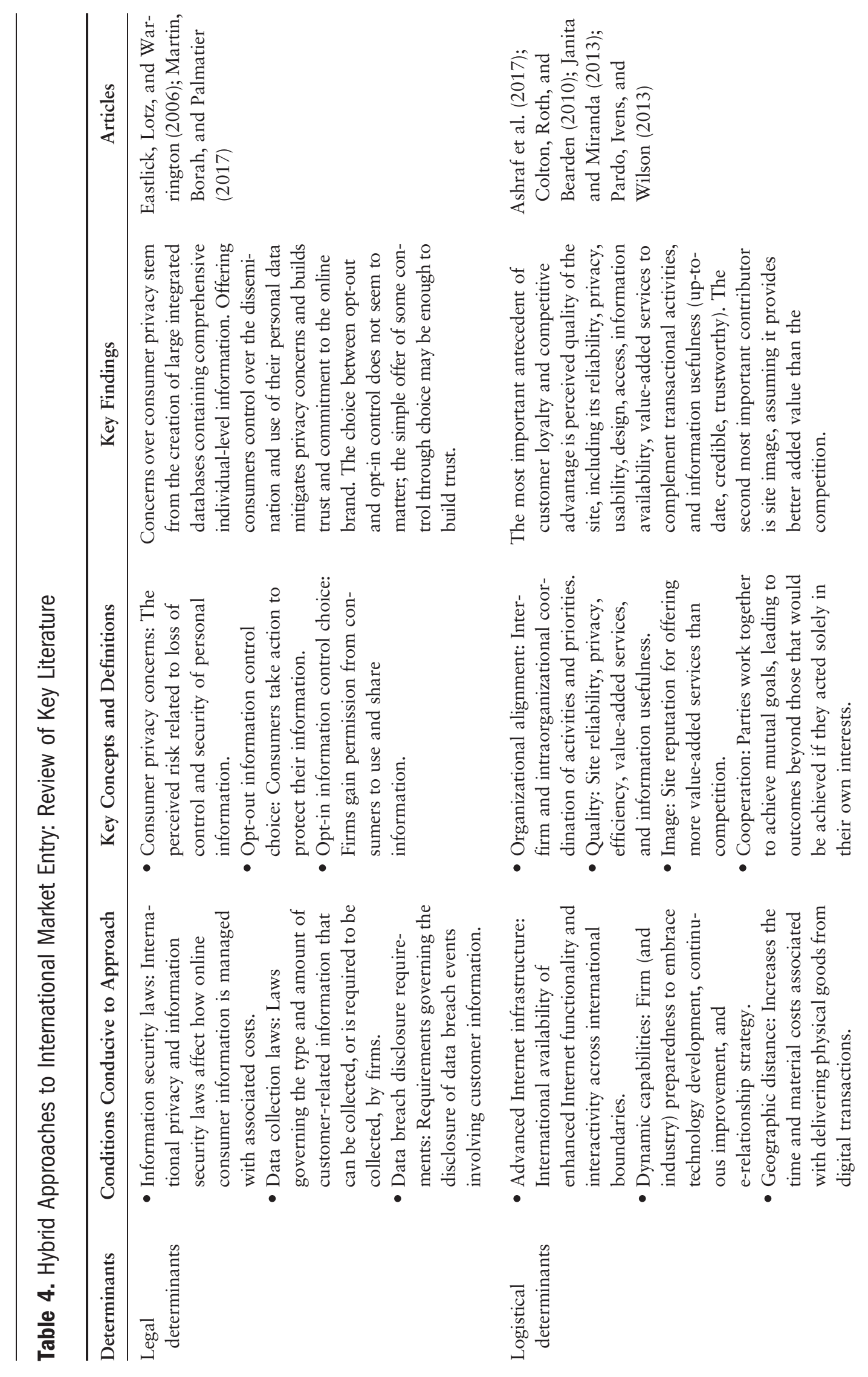

International Market Entry Strategies 41 




42 Journal of International Marketing 
distortions in information exchanges due to the institutional dissimilarities in foreign channels will influence perceptions of legitimacy and market ambiguity between channel partners, which in turn inform the optimal governance choices for minimizing adverse performance impacts (Leonidou et al. 2014). To help overcome institutional distance and unfamiliarity, relationship-building activities can strengthen channel networks of associated suppliers, distributors, and retailers that deliver market offerings to end users through a better coordination of focal firm efforts, as well as by insulating these networks from competitive forces (Palmatier et al. 2006). Similarly, firms' abilities to access or develop foreign-channel networks can offer superior information processing, knowledge creation, and adaptive abilities (Rothaermel, Kotha, and Steensma 2006). Relationship-specific investments can assist in alleviating these difficulties by strengthening relational bonds, creating value, lowering exchange costs, and providing an avenue for innovation and cocreation of knowledge to improve exchange performance (Akaka, Vargo, and Lusch 2013; Skarmeas, Katsikeas, and Schlegelmilch 2002).

Market Considerations. Physical and psychological distance, risk of opportunism, environmental turbulence, risk of communication misunderstanding, and even the threat of outright deception tend to be substantial in cross-border interfirm relationships. A willingness to adjust to the market is key; if a market is characterized by intense competition and low uncertainty, relying too much on relational ties may prove problematic (Kostova 1997). Taking a more transactional approach that acknowledges competitive market forces, customizes channel contracts, and includes additional monitoring thus may be a better short-term strategy. Economic and political instability (i.e., environmental turbulence) may favor a relational market orientation with less reliance on formal contracts and formal planning, due to the need for greater flexibility. Markets characterized by higher levels of uncertainty also may require more relational marketing effort and increased levels of communication to engender trust, minimize perceived opportunism, and increase perceptions of trustworthiness (Samaha, Beck, and Palmatier 2014). Consequently, the relational capabilities of firms operating in complex international markets play a critical role in determining market growth and financial performance, in part due to their risk mitigation effects (Griffith and Zhao 2015; Samiee, Chabowski, and Hult 2015).

Cultural Considerations. Cultural differences may lead to misinterpretations of specific business practices, communication styles, institutional/power structures, or governance mechanisms (Yang, Su, and Fam 2012). Cultural factors, such as individualism-collectivism, acceptance of power distance, preferences for uncertainty avoidance, and dominance of masculinity or femininity values in social interactions, can have profound impacts on the effectiveness of relational approaches (Samaha, Beck, and Palmatier 2014). Although channel partners acting in the best interest of committed, well-trusted sellers discourage opportunistic behavior, "outsider" firms that seek to enter lower-trust societies often find that a relational orientation is appropriate only for “insiders" (Wang 2007). Relational market orientation, cross-cultural training, and frequent visits to foreign exchange partners reduce psychic distance and can promote more accurate assessments of differences between home and foreign markets, as well as a greater willingness to interact in foreign-country contexts (with standardization or adaptation strategies), which ultimately should lead to performance gains (Conway and Swift 2000; Skarmeas, Katsikeas, and Schlegelmilch 2002). However, patience, time, and substantial resources are also required to build managerial ties and genuine personal relationships with key stakeholders (i.e., relationship-specific investments). Should managers decide to make such investments, the resulting relational approaches can increase firm credibility and ultimately improve exchange performance (Voldnes, Gronhaug, and Nilssen 2012).

For relational approaches to IME to succeed, managers must recognize, understand, and adapt to the contextual factors of a foreign market, which inform the relative effectiveness of relational strategies in transactions characterized by geographic distance and economic, cultural, and political differences (Samaha, Beck, and Palmatier 2014). Logically, international exchange relationships should include elements of both relationship-building strategies and prudent contractual governance for optimal performance because they represent complementary rather than mutually exclusive orientations (Seshadri and Mishra 2004). For example, relational governance may take precedence over contractual governance in uncertain markets, to incorporate appropriate levels of flexibility and tolerance (Griffith and Zhao 2015), but transactional approaches may tend to work better in stable markets or when the investment costs of relational strategies substantially outweigh their potential benefits.

\section{Digital Approaches to IME}

Internet communication technologies have a significant and growing influence on business transactions in many markets (Janita and Miranda 2013; Mathews et al. 2016). These communication advances enable businesses to identify and exploit market opportunities faster and across wider geographic areas than was previously possible (Creed, Zutshi, and Ross 2009). Although 
entrepreneurs have developed entirely new business models to exploit these technological developments, such business environments are also fraught with substantial risk and widespread influence, as demonstrated by the dot-com boom (and bust) of the early 2000s.

Legal Considerations. Advances in digital technologies prompted a multitude of new considerations for marketing managers in this domain, especially in relation to the availability and dissemination of information (Varadarajan and Yadav 2002). Legally, these new information flows are subject to varying regulations across markets. Local government regulations may exhibit varying degrees of openness to foreign firms operating freely online, differing levels of transactional integrity, and divergent approaches to the protection and enforcement of digital piracy. Moreover, firms may find themselves subject to digital espionage attempts from foreignmarket firms and even government agencies (Reinmoeller and Ansari 2016), all of which necessitate a strong understanding of the legal protections available to firms entering new foreign markets, as well as avenues for protecting intangible firm assets.

Logistical Considerations. Other features also differentiate digital environments from traditional IME settings, such as the reduced (electronic) proximity between buyers and sellers and varying temporal distances (i.e., time between purchase and receipt is greater for physical goods but lesser for digital products) (Simmons 2008). As information availability and dissemination has enabled increased firm learning and knowledge about new markets and new customers, it has also had profound effects on the decentralization of channel structures and the development of interorganizational networks (Gupta 2008; Yadav and Pavlou 2014). Digital infrastructures enable both the ability to find new channel partners in foreign markets (Petersen, Welch, and Liesch 2002) and new, digital-only business models that easily cross national boundaries (e.g., software as a service [SaaS]). For example, start-up businesses operating within the digital space automatically have the potential to be born global, due to the very nature of the digitally mediated, real-time communication channels that connect buyers and sellers from all over the world (Watson et al. 2015b). Furthermore, the physical infrastructure of channels has become more distributed and accessible, due to developments in technological platforms such as cloud computing (e.g., Amazon Web Services, Microsoft Azure, Google Cloud Platform) and point-of-sale online payment processing (e.g., Square, Shopify) that previously were prohibitively difficult or expensive to adopt. Accordingly, firms that are motivated to improve their capabilities with IT resources tend to gain more (Yadav and Pavlou 2014).
Market Considerations. For customers, Internet-enabled technologies make comparisons easier and support competitive evaluations, by offering multiple sources of credible information about the price and nonprice attributes of potential channel partners. Firms and customers that rely on digital technologies in their marketing and purchasing practices benefit from rich information, obtained with lower search costs (Häubl and Trifts 2000), which can reduce the information asymmetry between buyers and sellers and mitigate the potential for opportunism and conflict. For example, because digital approaches to marketing can serve as both distribution and promotion channels, they can reduce firms' marketing costs and increase their marketing efficiency (Varadarajan and Yadav 2002). The result is a more effective buyer-seller match, though there is a concomitant threat of increased competition, only a click away. Continued technological developments in digital communication technologies and the accessibility (and decreasing prices) of smartphones have had enormous implications for expanding straight-tocustomer IME strategies in lower-income economies (via channel disintermediation); yet firms still need to adapt their mobile IME strategies to match the readiness of local markets (Ashraf et al. 2017; Mathews et al. 2016). The average global selling price of smartphones has fallen by approximately $25 \%$ since 2011 (Saadi 2017), and this price trend has enormous potential to extend levels of digital economic development in developing markets, thus enabling firms to access millions of potential new customers.

Cultural Considerations. Finally, digital approaches to IME represent a firm resource that can establish a foundation for specific marketing capabilities. Empirical evidence supports the indirect influence of Internet marketing capabilities on international firm performance (e.g., international sales, market growth) through positive effects on information availability and international network capabilities (Mathews et al. 2016). When combined with foreign-market information, these capabilities help reduce liabilities in unfamiliar cross-border and cross-cultural environments (Kotha, Rindova, and Rothaermel 2001). The effective use of digital information technologies also can facilitate valuable learning about foreign markets and potential international customers, including cultural, political, and economic contexts, which may help assuage information asymmetry and the sense of "foreignness" (i.e., cultural distance) (Mathews et al. 2016). Managers develop firm resources when they combine existing marketing processes, skills, and information with IT resources to enhance capabilities pertaining to sales force systems, channel management and support, competitive intelligence, operational efficiency, and marketing-mix decisions tailored to new markets (Ray, Barney, and Muhanna 2004; Gabrielsson and Gabrielsson 2011). 
For example, web-based technologies can build an international customer base, provide information, enable price-based competition, and facilitate CRM (Verma, Sharma, and Sheth 2016). Improved technology capabilities and cost reductions enable trends toward greater market customization of product, promotion, pricing, distribution, and innovation (Pazgal and Soberman 2008). Yet, customers also perceive digital approaches as riskier and less trustworthy than face-to-face settings (McCole 2002), so the application of traditional relationship-marketing strategies through digital means (i.e., hybrid approaches) may have substantial value for firms, especially in complex and competitive international marketplaces.

\section{Hybrid Approaches to IME}

Hybrid approaches to IME blend relational and digital strategies, increasing the potential complexity of firm efforts to enter a market. Not only must firms overcome risks associated with the local market, they must do so within the constraints of digital environments that can limit the level of interpersonal interactions that help build strong buyer-seller relationships.

Legal Considerations. A substantial function of CRM is to procure timely, accurate information about customers, so legal stipulations relating to the ability to gather, use, and protect digital metrics of customers may pose substantial operational difficulties and compliance costs (Sen and Borle 2015). In part, this challenge reflects concerns about customer data privacy stemming from the creation of large, integrated databases that contain comprehensive, individuallevel information. Offering consumers control over the dissemination and use of their personal data mitigates privacy concerns and builds trust and commitment to the online brand (Tucker 2014). The choice between opt-out versus optin methods does not seem to matter; the simple offer of some form of control to the customer may be sufficient to build trust (Martin, Borah, and Palmatier 2017). Yet, some basic level of trust in the reliability and security of Internet-enabled communications systems must exist; nascent relationships can deteriorate quickly following even minor breaches of intangible customer assets, such as account and usage information (Eastlick, Lotz, and Warrington 2006; Martin, Borah, and Palmatier 2017).

Logistical Considerations. In digital environments, the perceived quality of the site, including its reliability, privacy, usability, design, access, information availability, valueadded services to complement transactional activities, and information usefulness (up-to-date, credible, trustworthy data) represent primary antecedents of customer loyalty and competitive advantage (Janita and Miranda 2013). That is, a well-executed digital environment provides the foundation for hybrid strategies, but rapid rates of technological change necessitate constant reevaluations of hybrid approaches. Central to such ongoing assessments is the maintenance of close channel-member relationships, which are critical for executing the accurate, reliable, logistically challenging fulfillment of products and services in digital exchanges (Colton, Roth, and Bearden 2010). These buyer-supplier relations can be a source of competitive advantage if they are imperfectly imitable, which becomes increasingly difficult to achieve in the face of more distributed and accessible value chains in the channel. Furthermore, the accessibility of end users to upstream firms increases with the proliferation of Internet access provided by increasingly affordable computers and smartphones (Ashraf et al. 2017), which heightens the need for effective multichannel strategies to prevent conflict with existing channel relationships, as well as effective management of new end user relationships after disintermediation (Srinivasan and Moorman 2005).

Market Considerations. Early relationships in digitally mediated contexts often feature a transactional approach, with low levels of engagement and trust, a strong emphasis on price, a high tendency to switch, and greater risk perception (Brun, Durif, and Ricard 2014; Zhang et al. 2016). In highly competitive digital markets, incumbent firms in the local market tend to be better attuned to local conditions. However, as exchange frequency increases-supported by transparent, effective, reliable, secure, Internet-enabled communication systems - trust in the company and engagement levels rise, while perceived risk and switching tendencies decrease (Conway and Swift 2000). Beyond technical capabilities, brand strength offers another means to mitigate the uncertainty, turbulence, and potential confusion of digital markets (Morgan-Thomas and Veloutsou 2013). Hybrid approaches can have distinct effects for various firm outcomes. For example, online platform providers generate much of their revenues from pay-per-click search advertising, payper-impression display advertising, and membership fees. High-trust, committed customers generate less search advertising revenue than low-trust, organic visitors, but they are more effective for generating display advertising and membership fee revenue, due to their greater engagement and time spent on the platform (Kozlenkova et al. 2017). By creating customer bonds, through connections to a brand's emotionally laden values, firms can produce relational experiences, even in digital settings (Wang, Pauleen, and Zhang 2016). A strong brand reputation also decreases psychological barriers and increases feelings of technological self-efficacy, which should enhance the perceived ease of use of online exchanges (Song et al. 2010). 
Cultural Considerations. Cultural differences across markets can alter the effectiveness of relational strategies used in digital settings, so firms must acknowledge the advantages and shortcomings of their technological choices. Relational approaches through digital settings often lack the interpersonal interactions that tend to drive trust, but they generate advantages associated with increased levels of convenience, speed, and efficiency (Bhatnagar and Ghose 2004). Moreover, channel partners may perceive technologically mediated exchanges as less friendly and more transaction focused than face-to-face exchanges, because the lack of human interaction eliminates various tangible and sensory cues (Keeling, Keeling, and McGoldrick 2013). To overcome these concerns, firms have sought to expand the functionality, flexibility, and feedback opportunities in their digital interactions (Keeling, Keeling, and McGoldrick 2013), as well as social cues, by implementing relational schema and performance scripts (Bickmore and Picard 2005). The extent to which such interactions produce transparency, accountability, feedback opportunities, and expectations of reciprocity defines their influence on customer perceptions of quality, friendliness, and satisfaction in the exchange (Keeling, Keeling, and McGoldrick 2013). Ultimately, establishing interactions with customers remains a primary goal of firms that employ hybrid approaches to IME, for which engagement, trust, and commitment still constitute the central elements of effective CRM in digitally mediated exchanges.

Digitally mediated channels have led to the development of new business models of international buyer-seller value exchanges (Janita and Miranda 2013; Mathews et al. 2016) that recognize the need to adapt extant relational strategies to leverage the advantages available through these technologies. As this review and synthesis of literature highlights, digital interactions with customers occur in substantially different environments than the conventional settings addressed by extant relationship-marketing literature. To exploit the multitude of opportunities afforded by digital platforms, hybrid approaches can adapt relational tactics to accommodate unique business environments. In particular, they should concentrate on core relational issues (e.g., trust, privacy, security, information sharing, bilateral communication, shared learning) — which are relatively more difficult to achieve with digital IME strategies.

\section{TAXONOMY OF RELATIONAL, DIGITAL, AND HYBRID MARKET ENTRY STRATEGIES}

Taxonomic analysis in marketing originates in strategic management literature and is useful to identify and describe strategies for firms in competitive markets (Jap and Mohr 2002; Namiki 1994; Porter 1980). Taxonomies are based on the principle that the strategies adopted by firms in different classifications indicate relatively heterogeneous strategic behaviors, but firms in the same classification demonstrate homogeneous strategic behaviors (Cavusgil, Chan, and Zhang 2003). In this section, we propose a taxonomy of IME strategies based on a firm's simultaneous implementation of digital and relational approaches, as a basis for our topological identification. Figure 2 provides a visual representation of our IME taxonomy, which crosses high and low levels of digital and relational IME strategies to define four main categories: traditional, relational, digital, and hybrid. In line with each type, we provide concrete examples of IME approaches (e.g., licensing, joint ventures, pure digital delivery, SaaS), discuss relevant conditions that influence success or failure in each context, and offer short cases to illustrate the managerial considerations in both successful (Table 5) and unsuccessful (Table 6) implementations.

In line with each type, we provide concrete examples of IME approaches (e.g., licensing, joint ventures, pure digital delivery, SaaS), discuss relevant conditions that influence success or failure in each context, and offer short cases to illustrate the managerial considerations in both successful and unsuccessful implementations. Figure 2 provides a visual representation of our IME taxonomy, which crosses high and low levels of digital and relational IME strategies to define four main categories: traditional, relational, digital, and hybrid.

\section{Low Digital-Low Relational: Traditional Strategies}

Traditional IME strategies refer to planned systems of delivering and distributing goods and services to an international market through foreign-channel intermediaries. Before the development of Internet-enabled communications, conventional IME strategies focused on manufactured goods and the need to secure tangible firm assets and monitor international partners, so they gave rise to approaches designed to bridge or avoid differences across countries (Akaka, Vargo, and Lusch 2013). For example, with a pure exporting strategy, a firm can sell and ship its domestically manufactured goods to a foreign distributor in the desired market without requiring a physical presence in the country. Licensing agreements (e.g., Microsoft Enterprise Agreements) and franchising (e.g., Hertz corporate car rentals in Europe) also allow firms to enter international markets by assigning most of the capital risk to local agents. If the firm's offerings demand complex manufacturing techniques, it may prefer fully integrated production, such as through the purchase of a local firm, or foreign direct investment to build physical assets in foreign markets. Such options are prevalent in the services sector, too, such as when a consulting firm sets up offices abroad 
Figure 2. Taxonomy of IME Strategies

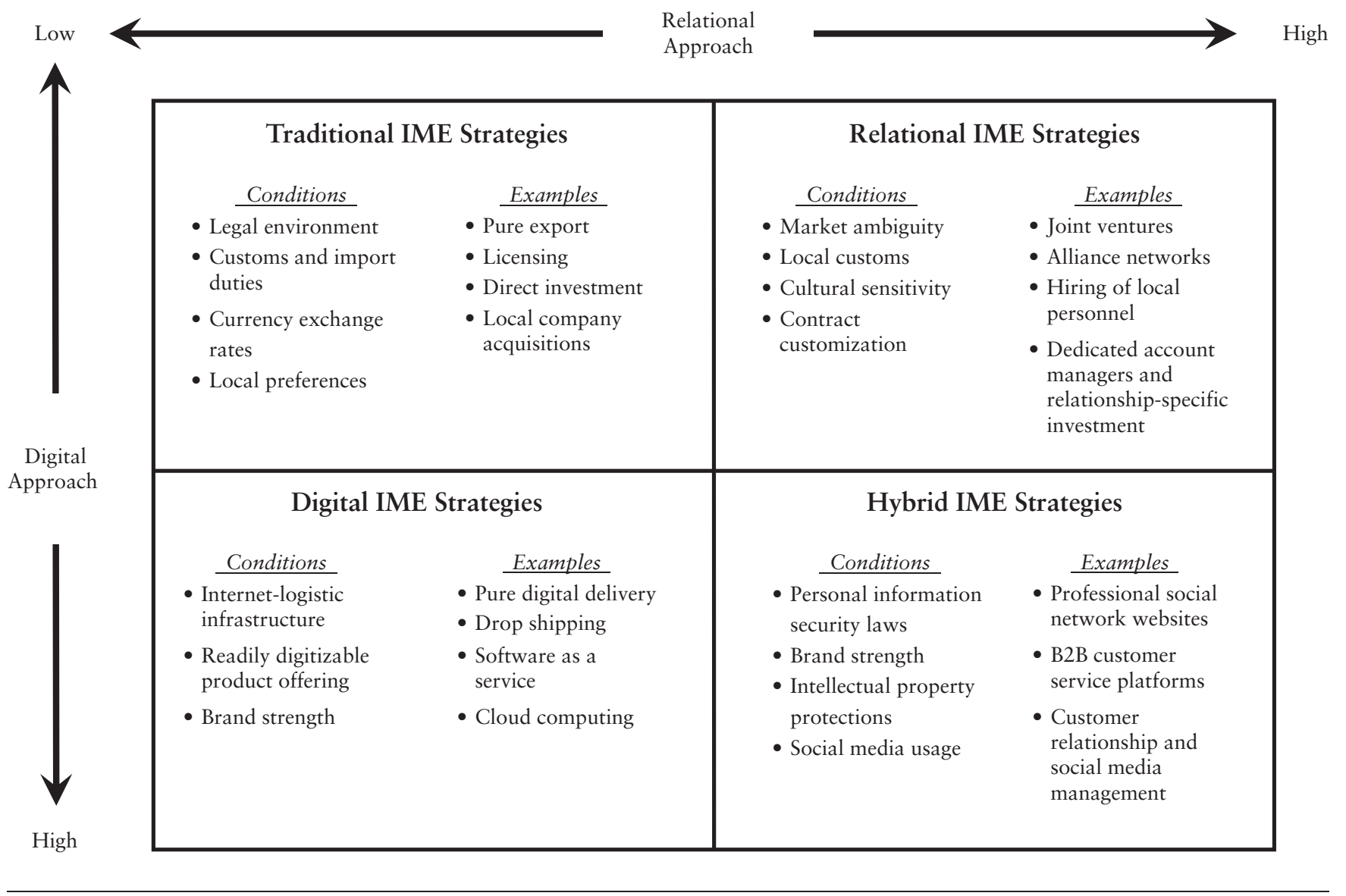

to ensure control over its output to international customers (e.g., the Berlin offices of McKinsey \& Co.).

Such traditional IME strategies must account for distinctions between foreign and domestic environments, including differences in culture (language, tastes), currency, legal concepts, import duties and customs, and physical distance (Akaka, Vargo, and Lusch 2013). Culture largely determines whether firms can sell their products "as is" or instead should make significant changes or develop new offerings specific to the chosen market (Cavusgil, Deligonul, and Yaprak 2005). For example, UPS initially entered the Chinese market in 1988 on the strength of its export-import B2B services and chose to partner with local carriers for domestic delivery to learn the market, rather than directly transplant its U.S. model by purchasing its own Chinese air routes and acquiring local distributors (Gao and Prime 2010). Although this choice limited UPS's short-term growth, it was able to avoid the risks of what was then a volatile market, prior to China's entry into the World Trade Organization, while also learning that Chinese business customers preferred customized logistic services over standardized offerings. By 2002, Chinese exports helped UPS grow its revenues by $60 \%$. Fluctuations in exchange rates can also render firm offerings prohibitively expensive or, alternatively, so inexpensive that supply stock-outs become an issue. The varying legal and regulatory requirements across markets may also add costs (e.g., Japanese vs. U.S. environmental regulations) or threaten to put a firm in violation of legislation (e.g., European antitrust lawsuits against Microsoft).

\section{Low Digital-High Relational: Relational Strategies}

Relational IME strategies refer to firm actions that aim to build strong relationships with exchange partners to overcome exchange risks associated with foreign markets, including physical and psychological distance, opportunism, relational instability, communication difficulties, and deception 


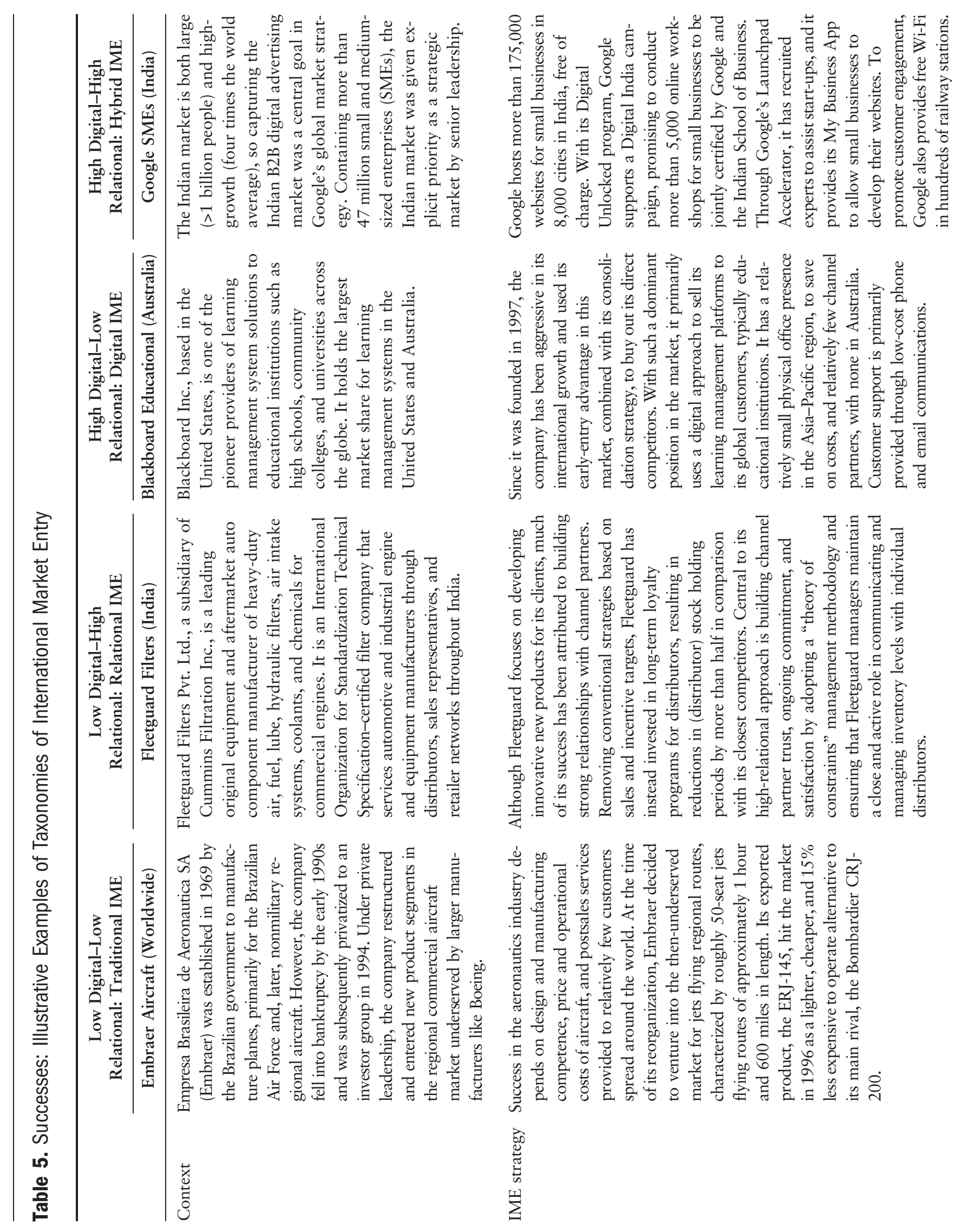

48 Journal of International Marketing 







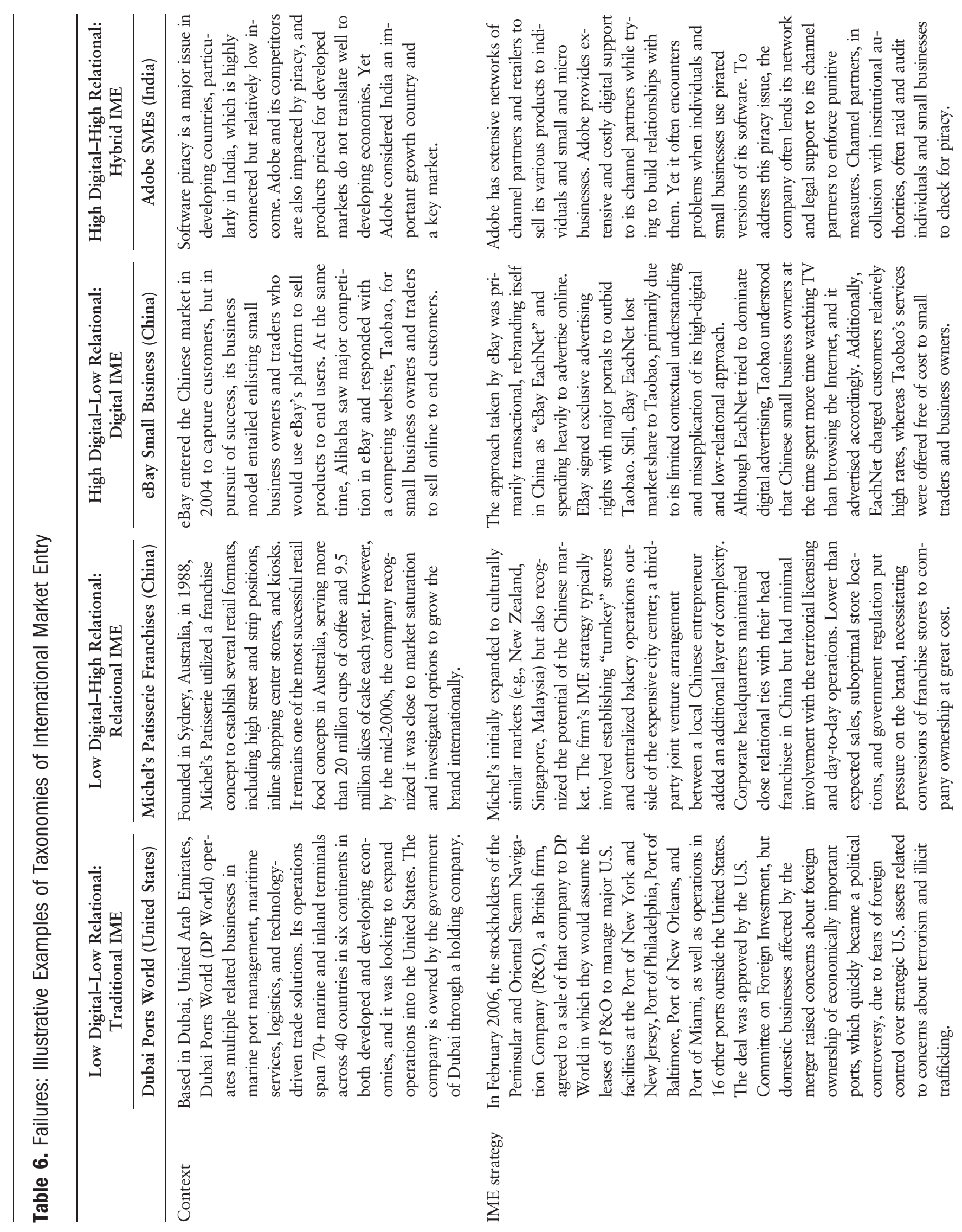

50 Journal of International Marketing 


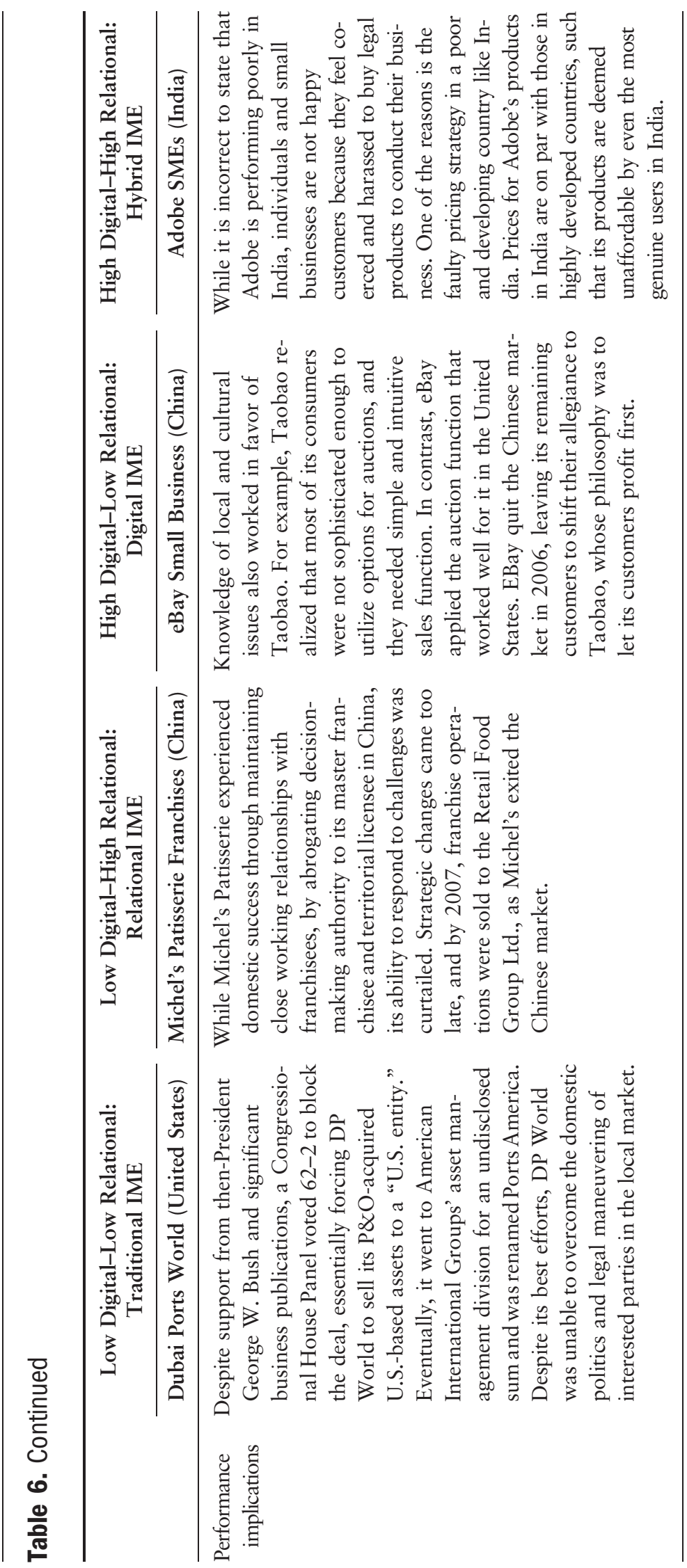

International Market Entry Strategies 51 
(Leonidou et al. 2014). Principally, relational approaches attempt to enhance commitment and trust (i.e., informal governance), often through relationship-specific investments or contractual obligations tailored to the local market (i.e., formal governance). These approaches take many forms, including joint ventures, alliance networks, cooperative planning, and hiring local personnel (Yang, Su, and Fam 2012). They encourage information sharing, flexibility, and solidarity, and in conjunction with flexible contracts, they can provide a foundation for establishing legitimized practices (Poppo and Zenger 2002).

In turn, various conditions influence the success of relationalfocused IME strategies. Market ambiguity or dynamic business environments often require increased communication, to engender trust and minimize perceptions of opportunism that may arise from the internal uncertainty that firms experience when entering foreign markets (Yang, Su, and Fam 2012). However, the scope and magnitude of relationship-specific investments must reflect the firm's competitive positioning in the marketplace because these investments could restrict expansion with other foreign partners or limit alternative opportunities (Skarmeas, Katsikeas, and Schlegelmilch 2002). Legal considerations include procedures to govern information sharing, joint codes of conduct and monitoring, mediation, responsibility guidelines, and ethical codes that align with the local market (Leonidou et al. 2014). Cultural sensitivity to laws and legal practice is also paramount to success and may explain why relationship-marketing activities achieve varying levels of effectiveness across international borders (Samaha, Beck, and Palmatier 2014). For example, collectivist cultures often favor more relational flexibility, to ensure agility in uncertain political and economic environments. Accordingly, investments in cross-cultural training can promote better assessments of differences between domestic and foreign markets (Skarmeas, Katsikeas, and Schlegelmilch 2002).

\section{High Digital-Low Relational: Digital Strategies}

Digital IME strategies involve the arm's-length delivery and distribution of goods and services to a foreign market through Internet-enabled communication technologies. Through Internet-enabled communications, modern businesses can identify and exploit market opportunities faster and across wider geographic areas (Creed, Zutshi, and Ross 2009), as well as develop new business models to connect sellers and buyers interested in transactional exchanges of both goods and services. For example, manufacturers can sell through multiple international online affiliates that provide independent expertise, reviews, and information in a commission-only model (Gilliland and Rudd 2013).
Technology developments also facilitate purely digital approaches, such as SaaS (e.g., Dropbox) and pure digital delivery (streaming video subscriptions, multiplayer gaming), which often derive revenues from pay-per-click search advertising, pay-per-impression display advertising, or membership fees (Edelman 2014).

Such digital approaches naturally occur for products and services that can be readily distributed through digital platforms and for physical products that benefit from digital augmentation (e.g., exclusive web-based content with purchase of Adobe Analytics). They depend on the accessibility, penetration, capacity, functionality, and efficiency of the Internet and web-based infrastructure (Tiago and Verissimo 2014). Firm experience and internal technological capabilities also determine the success of digital initiatives. Less concentrated industries (i.e., with more and highly fragmented intermediaries) tend to lead firms to embrace direct marketing through e-marketplaces, but high concentration at this intermediary level creates a threat of retaliation, thereby disincentivizing firms from marketing directly to customers (Varadarajan and Yadav 2002). To gain competitive advantages, e-tailers must work closely with suppliers to ensure product availability, efficient order processing, and transportation (Colton, Roth, and Bearden 2010). Brand strength also influences this competitive advantage and the effectiveness of a digital strategy in a global marketplace. If firms rely on foreign-market distributors for the efficient delivery of goods, foreign labor laws will affect their digital strategy (Tiago and Verissimo 2014). Furthermore, firms must protect their digital offerings from piracy and need access to independent third-party audits of search engines to detect fraud. These efforts largely depend on the foreign market's legal statutes and enforcement mechanisms.

\section{High Digital-High Relational: Hybrid Strategies}

Hybrid IME strategies refer to firm actions that blend customer relationship building into digital channels of delivery and distribution of goods and services to a foreign market. In a landscape in which digital marketing is fundamental to business (Brun, Durif, and Ricard 2014; Mathews et al. 2016), relational strategies require adaptation to exploit modern technological advantages, especially those that facilitate exchanges. Relational approaches integrated into digital environments help alleviate the risk perceptions that arise in purely digital contexts. For example, digital service providers such as ZenDesk help business customers handle their own customer service issues related to digital exchanges. Digital, technology, and social media platforms also make it possible for a new type of firm to help customers 
develop professional relationships (e.g., LinkedIn, AngelList) or customer relationships (e.g., Salesforce, HootSuite).

In addition, online retailing and relationship-marketing management help expand foreign markets by combining the advantages of digital approaches (e.g., convenience, availability of information) and relational approaches (e.g., risk mitigation, governance). Hybrid approaches can supplement or replace offline relationship-marketing efforts (Keeling, Keeling, and McGoldrick 2013), such as when social media encourage e-relationship and brand development or increase customers' readiness to engage with digital communication and transaction technologies (Brun, Durif, and Ricard 2014). Firm technology that demonstrates trustworthiness (e.g., minimizes security risks, increases price consistency) can generate cooperation and commitment. Because digital purchases also involve transactions of sensitive information, legal considerations also can be substantial. Depending on the local market, laws surrounding privacy and personal information security will affect the management of online customer data, particularly in markets in which governments monitor online activities (Eastlick, Lotz, and Warrington 2006). International marketers must define desirable levels of transparency for both data and technology across different markets while combating leakage to competitors; weak or nonexistent legal protection for intellectual property can threaten the survival of firms entering international markets (Wang, Pauleen, and Zhang 2016). Cultural factors also warrant consideration (Morgan-Thomas and Veloutsou 2013). For example, managers should design and test communications for receptivity by customers to ensure they are acceptable in different cultural contexts. Social media and other digitally delivered relational approaches also should include appropriate social cues, images, and communications to avoid misunderstanding or relationship damage.

\section{Taxonomic Summary}

Increasing customer familiarity with (and use of) technologymediated firm interactions presents both risks and opportunities for firms entering foreign markets. In particular, the value of relational approaches increases, due to the enhanced risk, which in turn is a result of the legal, logistical, market, and cultural realities of the local environment. Whether firms need to safeguard their tangible firm assets to enter a foreign market (e.g., supply chains, distribution channels) or must protect intangible customer assets (e.g., personal information, location data, usage behavior), they must consistently establish and maintain customer trust. Thus, relational approaches are well suited. However, a core difficulty for marketers lies in finding ways to adapt their relational approaches to accommodate growth in the use of digital interfaces, particularly considering the accelerating rate of technological change.

\section{RESEARCH AGENDA AND DIRECTIONS}

Despite their enormous influence, Internet-enabled technologies remain at a relatively nascent stage of development; they stand poised to exert even greater impacts on business strategy and practice in the next 30 years. Our review and analysis of prior literature leads us to believe that three main topics are likely to establish important avenues for research: the ubiquity of datarich marketing environments, marketing automation, and artificial intelligence. Each area has potentially vast implications for developing trust and commitment in buyer-seller relationships, as well as expanding firm knowledge and learning. Along these lines, they hold potential to substantially influence various measures of firm performance across multiple time horizons.

\section{Data-Rich Environments}

Modern businesses can capture, integrate, and use data from multiple sources, which provides opportunities to gain insights into current marketing practices and develop firm knowledge as a basis for establishing new marketing strategies (Sun 2006). Analyzing data from multiple sources can be advantageous in terms of gaining new customers and improving the engagement of existing customers, through a deeper understanding of their needs. Likewise, firms can better understand the influences of competitors, foreign markets, and new product opportunities - all in real time. Data-rich marketing environments enable firms to include more parameters in their analyses of new customers or market opportunities (e.g., trend mining with marketing analytics), extract more value, and more accurately measure advertising campaign results (Weinberg, Davis, and Berger 2013). Relatedly, they facilitate quick historical comparison to past product-market performance benchmarks such as unit sales, as well as customer behavior like acquisition and retention metrics, for more effective managerial decision making (Katsikeas et. al 2016). The collection, analysis, and exchange of big data should extend firms' relational capabilities in international markets and elicit greater trust and relational commitment, due to increased transparency (e.g., communication) and more in-depth customer knowledge. This, in turn, may also improve the speed and success of international expansion by increasing local market legitimacy (Wu and Zhou 2017). However, some caveats to the use of big data remain. Companies such as Amazon and Facebook note increasing concerns about how customers perceive their data collection approaches, with the recognition that excessive data collection may create customer 
(and community) reactance and dissent that could harm profitability and brand value (Swant 2016). It also would be valuable to examine potential power and dependency changes in international business relationships when one channel partner controls the bulk of the exchange information, as is the case with infomediaries, two-sided platforms, B2B auctions, and other electronic marketplaces (Gal-Or and Gal-Or 2005; Lancastre and Lages 2006). Such informational advantages may destabilize international relationships if less dependent (more powerful) relational partners exhibit opportunistic behaviors (Geyskens et al. 1996).

\section{Marketing Automation}

Marketing automation extends traditional marketing methods by gathering information from multiple data sources and then altering marketing content rapidly as needed (Hunter and Perreault 2007). In turn, data availability is critical for the effective automation of firm leaning and knowledge implementation, which requires accurate assessments of dynamic customer preferences (Heimbach, Kostyra, and Hinz 2015). Marketing automation makes it possible to customize or personalize marketing-mix elements to targeted customer segments and seamlessly manage channel partner logistics; yet it can be difficult to execute complex operations in digitally mediated environments (Heimbach, Kostyra, and Hinz 2015). Customers respond to customized offerings with greater involvement or engagement, due to the relevance of the marketing information (Järvinen and Karjaluoto 2015). In this case, the benefits include enhanced customer conversion rates, cross- and up-selling outcomes, and improved customer retention rates. Similarly, customer experience with automated services is likely to impact real-time customer mindset performance outcomes like satisfaction and attitudinal loyalty (Katsikeas et al. 2016), both of which are linked to accounting and financial performance of the firm (Watson et al. 2015a). Automation holds promising advances for sales force management as well. For example, Hunter and Perreault (2007) find that using sales technologies to analyze and communicate information has a positive effect on salespeople's customer relationship-building performance but a negative effect on their administrative performance (e.g., submitting required sales reports). They posit that such effects imply a trade-off between selling and nonselling responsibilities. Considering that marketing automation leverages relevant, timely information, automating certain internal marketing processes may prove beneficial for leveraging digital and hybrid IME relationship-building strategies.

To date, relatively little research has investigated the implications of increased uses of automation in marketing or its effect on buyer-seller relationship quality, suggesting potentially fruitful avenues for research. For example, do greater levels of automation stress relationship quality because the partner increasingly is serviced by automated, digital processes rather than account managers? Can automated processes focused on one market work well in an international expansion? Studies of how international partners might share responsibilities for the design and administration of automated content-especially from power, dependence, and information asymmetry perspectives-are likely to be insightful. On a related note, many firms have outsourced or offshored their CRM processes, precisely in response to the emergence of global, low-cost, high-speed communication and information processing networks (Kalaignanam and Varadarajan 2012), yet the effects of automation are still not well known over the customer life cycle. For example, some call centers offer varying levels of customer service depending on a customer's profitability and will assign customers with lower lifetime value to automated, menu-based service (Zeithaml, Rust, and Lemon 2001). Accordingly, we suggest the need to investigate the extent that automating potentially important relationship-building interactions may help or hinder customer expansion and retention across multiple sociocultural contexts.

\section{Artificial Intelligence}

There is ample scope for the practical application of artificial intelligence (AI) to IM, precisely due to its potential to exploit the ubiquity of data-rich marketing environments for firm learning and knowledge. For example, self-organizing maps based on artificial neural networks can assist small businesses in making decisions about optimal overseas market locations (Fish and Ruby 2009). To advance such insights, researchers might consider ways that AI can supplement managerial decision making about market entry, channel partner selection, product optimization, pricing decisions, and advertising strategies. Effectively implemented, AI systems are likely to outperform statistical-based tools for complex, qualitative, or difficult-to-program marketing problems and decision scenarios (Martínez-López and Casillas 2013); yet researchers and practitioners are still working to realize this promise. Relatively little literature links the use of AI to marketing applications (Casillas and Martínez-López 2009), such as the use of AI to analyze massive, user-generated data or support finer judgments about customer groups in diverse international market contexts (Cooke and Zubcsek 2017). Likewise, AI holds substantial promise pertaining to forward-looking operational performance gains, such as forecasting and evaluating new-product success or market entry timing decisions (Katsikeas et al. 2016; Wu and Zhou 2017). 
Nor is there sufficient research into the opportunities for using AI systems to interact with and enhance interorganizational trust and commitment in business settings. For example, how might AI supplement or replace customer service representatives and salespeople? Early studies describe how AI helps salespeople target and acquire new customers more efficiently (D'Haen and Van den Poel 2013), but they ignore its potential for carrying out relationship-building activities. To what extent might the use of AI by boundary spanners hinder or enhance trust and commitment? Moreover, marketers and researchers lack clear guidelines about the contexts in which AI is more appropriate or effective for building customer relationships and whether customers will be receptive to these technologies, especially if they minimize human interactions. Avatars (i.e., digital simulations of salespeople or assistants) might increase social presence cues and facilitate trust, and some evidence suggests that their use can improve the overall customer online experience (Holzwarth, Janiszewski, and Neumann 2006). However, evidence of the acceptability and influence of avatars in virtual environments is equivocal, and some findings challenge the universality of customer acceptance or perceived usefulness in various transnational contexts (Mahdjoubi, Koh, and Moobela 2014).

\section{Conclusion}

The adoption of digital communications technologies has been one of the most significant developments in business since the mid-1990s. With the development of the Internet and its penetration into developing economies, dramatic increases in the globalization of media, culture, and thought have prompted firms to bypass local relational infrastructures and enter foreign markets with a digital (transactional) or hybrid digital-relational strategy. This article provides context and direction for academic researchers and marketing professionals working on IME topics, by highlighting the development of academic research in this domain; reviewing and synthesizing pertinent theory associated with relational, digital, and hybrid approaches to IME; providing a taxonomy of modern IME strategies and illustrative case studies; and suggesting potentially impactful areas for research based on their implications for firm learning and knowledge, as well as interorganizational trust and commitment.

\section{REFERENCES}

Achrol, Ravi S., and Philip Kotler (2012), "Frontiers of the Marketing Paradigm in the Third Millennium," Journal of the Academy of Marketing Science, 40 (1), 35-52.

Akaka, Melissa Archpru, Stephen L. Vargo, and Robert F. Lusch (2013), "The Complexity of Context: A Service
Ecosystems Approach for International Marketing," Journal of International Marketing, 21 (4), 1-20.

Anderson, Erin, and Anne T. Coughlan (1987), "International Market Entry and Expansion via Independent or Integrated Channels of Distribution," Journal of Marketing, 51 (1), 71-82.

Anderson, James C., and James A. Narus (1990), “A Model of Distributor Firm and Manufacturer Firm Working Partnerships," Journal of Marketing, 54 (1), 42-58.

Ashraf, Abdul R., Narongsak Thongpapanl, and Seigyoung Auh (2014), "The Application of the Technology Acceptance Model Under Different Cultural Contexts: The Case of Online Shopping Adoption," Journal of International Marketing, 22 (3), 68-93.

Ashraf, Abdul R., Narongsak (Tek) Thongpapanl, Bulent Menguc, and Gavin Northey (2017), "The Role of M-Commerce Readiness in Emerging and Developed Markets," Journal of International Marketing, 25 (2), 25-51.

Baumgartner, Hans, and Rik Pieters (2003), "The Structural Influence of Marketing Journals: A Citation Analysis of the Discipline and Its Subareas over Time," Journal of Marketing, 67 (2), 123-39.

Berthon, Pierre, Leyland Pitt, Jean-Paul Berthon, Colin Campbell, and Des Thwaites (2008), "e-Relationships for e-Readiness: Culture and Corruption in International e-B2B," Industrial Marketing Management, 37 (1), 83-91.

Bhatnagar, Amit, and Sanjoy Ghose (2004), “Online Information Search Termination Patterns Across Product Categories and Consumer Demographics," Journal of Retailing, 80 (3), 221-28.

Bickmore, Timothy W., and Rosalind W. Picard (2005), "Establishing and Maintaining Long-Term Human-Computer Relationships," ACM Transactions on Computer-Human Interaction (TOCHI), 12 (2), 293-327.

Bowersox, Donald J., and Roger J. Calantone (1998), "Executive Insights: Global Insights," Journal of International Marketing, 6 (4), 83-93.

Brun, Isabelle, Fabien Durif, and Line Ricard (2014), "ERelationship Marketing: A Cognitive Mapping Introspection in the Banking Sector," European Journal of Marketing, $48(3 / 4), 572-94$.

Calantone, Roger J., and Yushan Sam Zhao (2001), “Joint Ventures in China: A Comparative Study of Japanese, Korean, and U.S. Partners," Journal of International Marketing, 9 (1), $1-23$.

Cannon, Joseph P., Ravi S. Achrol, and Gregory T. Gundlach (2000), "Contracts, Norms, and Plural Form of Governance," Journal of the Academy of Marketing Science, 28 (2), 180-94. 
Cano, Cynthia R., Francois A. Carrillat, and Fernando Jaramillo (2004), "A Meta-Analysis of the Relationship Between Market Orientation and Business Performance: Evidence from Five Continents," International Journal of Research in Marketing, 21 (1), 179-200.

Casillas, Jorge, and Francisco J. Martínez-López (2009), "Mining Uncertain Data with Multiobjective Genetic Fuzzy Systems to be Applied in Consumer Behavior Modeling," Expert Systems with Applications, 36 (2), 1645-59.

Cavusgil, S. Tamer, Kwong Chan, and Chun Zhang (2003), "Strategic Orientations in Export Pricing: A Clustering Approach to Create Firm Taxonomies," Journal of International Marketing, 11 (1), 47-72.

Cavusgil, S. Tamer, Seyda Deligonul, and Attila Yaprak (2005), "International Marketing as a Field of Study: A Critical Assessment of Earlier Development and a Look Forward," Journal of International Marketing, 13 (4), 1-27.

Cavusgil, S. Tamer, Seyda Deligonul, and Chun Zhang (2004), "Curbing Foreign Distributor Opportunism: An Examination of Trust, Contracts, and the Legal Environment in International Channel Relationships," Journal of International Marketing, 12 (2), 7-27.

Chabowski, Brian R., Jeannette A. Mena, and Tracy L. Gonzalez-Padron (2011), "The Structure of Sustainability Research in Marketing, 1958-2008: A Basis for Future Research Opportunities," Journal of the Academy of Marketing Science, 39 (1), 55-70.

Chakravorti, Bhaskar, Christopher Tunnard, and Ravi Shankar Chaturvedi (2015), "Where the Digital Economy Is Moving the Fastest," Harvard Business Review (February), 19.

Colton, Deborah A., Martin S. Roth, and William O. Bearden (2010), "Drivers of International E-Tail Performance: The Complexities of Orientations and Resources," Journal of International Marketing, 18 (1), 1-22.

Conway, Tony, and Jonathan S. Swift (2000), "International Relationship Marketing: The Importance of Psychic Distance," European Journal of Marketing, 34 (11/12), 1391-414.

Cooke, Alan D.J., and Peter P. Zubcsek (2017), “The Connected Consumer: Connected Devices and the Evolution of Customer Intelligence," Journal of the Association for Consumer Research, 2 (2), 164-78.

Creed, Andrew, Ambika Zutshi, and Jane Ross (2009), "Relational Ethics in Global Commerce," Journal of Electronic Commerce in Organizations, 7 (1), 35-49.

Deng, Ziliang, and Zeyu Wang (2017), "Early-Mover Advantages at Cross-Border Business-to-Business E-Commerce Portals," Journal of Business Research, 69 (2), 6002-11.
D'Haen, Jeroen, and Dirk Van den Poel (2013), “ModelSupported Business-to-Business Prospect Prediction Based on an Iterative Customer Acquisition Framework," Industrial Marketing Management, 42 (4), 544-51.

Douglas, Susan P., and C. Samuel Craig (2011), "Convergence and Divergence: Developing a Semiglobal Marketing Strategy,” Journal of International Marketing, 19 (1), 82-101.

Dunning, John H. (2009), "Location and the Multinational Enterprise: A Neglected Factor?" Journal of International Business Studies, 40 (1), 5-19.

Dwyer, F. Robert, Paul H. Schurr, and Sejo Oh (1987), "Developing Buyer-Seller Relationships," Journal of Marketing, 51 (2), 11-27.

Eastlick, Mary Ann, Sherry L. Lotz, and Patricia Warrington (2006), "Understanding Online B-to-C Relationships: An Integrated Model of Privacy Concerns, Trust, and Commitment," Journal of Business Research, 59 (8), 877-86.

Edelman, Benjamin (2014), "Pitfalls and Fraud in Online Advertising Metrics," Journal of Advertising Research, 54 (2), 127-32.

Elmer-Dewitt, Philip, and David S. Jackson (1994), "Battle for the Soul of the Internet," Time Magazine, 144 (4), 50-57.

Faccio, Mara (2006), "Politically Connected Firms," American Economic Review, 96 (1), 369-86.

Fish, Kelly, and Paula Ruby (2009), "An Artificial Intelligence Foreign Market Screening Method for Small Businesses," International Journal of Entrepreneurship, 13 (January), 65-81.

Gabrielsson, Mika, and Peter Gabrielsson (2011), "InternetBased Sales Channel Strategies of Born Global Firms," International Business Review, 20 (1), 88-99.

Gal-Or, Esther, and Mordechai Gal-Or (2005), "Customized Advertising via a Common Media Distributor," Marketing Science, 24 (2), 241-53.

Ganesan, Shankar (1994), "Determinants of Long-Term Orientation in Buyer-Seller Relationships," Journal of Marketing, 58 (2), 1-19.

Gao, Hongmei, and Penelope Prime (2010), "Facilitators and Obstacles of Intercultural Business Communication for American Companies in China: Lessons Learned from the UPS Case," Global Business Languages, 15 (1), 143-69.

Geyskens, Inge, Jan-Benedict E.M. Steenkamp, Lisa K. Scheer, and Nirmalya Kumar (1996), "The Effects of Trust and Interdependence on Relationship Commitment: A TransAtlantic Study," International Journal of Research in Marketing, 13 (4), 303-17. 
Gilliland, David I., and John M. Rudd (2013), "Control of Electronic Channel Affiliates: An Exploratory Study and Research Propositions," Journal of Business Research, 66 (12), 2650-56.

Griffith, David A., and Yanhui Zhao (2015), "Contract Specificity, Contract Violation, and Relationship Performance in International Buyer-Supplier Relationships," Journal of International Marketing, 23 (3), 22-40.

Grönroos, Christian (1990), "Relationship Approach to Marketing in Service Contexts: The Marketing and Organizational Behavior Interface," Journal of Business Research, 20 (1), 3-11.

Gupta, Sudheer (2008), "Channel Structure with Knowledge Spillovers,” Marketing Science, 27 (2), 247-61.

Häubl, Gerald, and Valerie Trifts (2000), "Consumer Decision Making in Online Shopping Environments: The Effects of Interactive Decision Aids," Marketing Science, 19 (1), 4-21.

Heimbach, Irina, Daniel S. Kostyra, and Oliver Hinz (2015), "Marketing Automation," Business \& Information Systems Engineering, 57 (2), 129-33.

Hillman, Amy J., Asghar Zardkoohi, and Leonard Bierman (1999), "Corporate Political Strategies and Firm Performance: Indications of Firm-Specific Benefits from Personal Service in the US Government," Strategic Management Journal, 20 (1), 67-81.

Hofstede, Geert H. (1980), Culture's Consequences: International Differences in Work-Related Values. Newbury Park, CA: Sage Publications.

Holzwarth, Martin, Chris Janiszewski, and Marcus M. Neumann (2006), "The Influence of Avatars on Online Consumer Shopping Behavior," Journal of Marketing, 70 (4), 19-36.

Hoppner, Jessica J., and David A. Griffith (2015), "Looking Back to Move Forward: A Review of the Evolution of Research in International Marketing Channels," Journal of Retailing, 91 (4), 610-26.

Hunter, Gary K., and William D. Perreault Jr. (2007), "Making Sales Technology Effective," Journal of Marketing, 71 (1), 16-34.

Jackson, Tyrone W. (2014), "Personalisation and CRM," Database Marketing \& Customer Strategy Management, 15 (1), 24-36.

Janita, M. Soledad, and F. Javier Miranda (2013), "The Antecedents of Client Loyalty in Business-to-Business (B2B) Electronic Marketplaces," Industrial Marketing Management, 42 (2), 814-23.
Jap, Sandy D. (2003), "An Exploratory Study of the Introduction of Online Reverse Auctions," Journal of Marketing, 67 (3), 96-107.

Jap, Sandy D. (2007), “The Impact of Online Reverse Auction Design on Buyer-Seller Relationships," Journal of Marketing, $71(1), 146-59$.

Jap, Sandy D., and Shankar Ganesan (2000), "Control Mechanisms and the Relationship Life Cycle: Implications for Safeguarding Specific Investments and Developing Commitment," Journal of Marketing Research, 37 (2), 227-45.

Jap, Sandy D., and Jakki J. Mohr (2002), "Leveraging Internet Technologies in B2B Relationships," California Management Review, 44 (4), 24-38.

Järvinen, Joel, and Heikki Karjaluoto (2015), "The Use of Web Analytics for Digital Marketing Performance Measurement," Industrial Marketing Management, 50, 117-27.

Kalaignanam, Kartik, and Rajan Varadarajan (2012), “Offshore Outsourcing of Customer Relationship Management: Conceptual Model and Propositions," Journal of the Academy of Marketing Science, 40 (2), 347-63.

Katsikeas, Constantine S., Neil A. Morgan, Leonidas C. Leonidou, and G. Tomas M. Hult (2016), "Assessing Performance Outcomes in Marketing," Journal of Marketing, 80 (March), $1-20$.

Keeling, Kathleen, Debbie Keeling, and Peter McGoldrick (2013), "Retail Relationships in a Digital Age," Journal of Business Research, 66 (1), 847-55.

Kevork, Eleni K., and Adam P. Vrechopoulos (2009), “CRM Literature: Conceptual and Functional Insights by Keyword Analysis," Marketing Intelligence \& Planning, 27 (1), 48-85.

Kim, Stephen K., Richard G. McFarland, Soongi Kwon, Sanggi Son, and David A. Griffith (2011), "Understanding Governance Decisions in a Partially Integrated Channel: A Contingent Alignment Framework," Journal of Marketing Research, 48 (3), 603-16.

Kogut, Bruce, and Harbir Singh (1988), “The Effect of National Culture on the Choice of Entry Mode," Journal of International Business Studies, 19 (3), 411-32.

Kostova, Tatiana (1997), “Country Institutional Profiles: Concept and Measurement," Academy of Management Proceedings, 1997 (August), 180-84.

Kotha, Suresh, Violina R. Rindova, and Frank T. Rothaermel (2001), "Assets and Actions: Firm-Specific Factors in the Internationalization of U.S. Internet Firms," Journal of International Business Studies, 32 (4), 769-91. 
Kozinets, Robert V., Kristine De Valck, Andrea C. Wojnicki, and Sarah J.S. Wilner (2010), "Networked Narratives: Understanding Word-of-Mouth Marketing in Online Communities," Journal of Marketing, 74 (2), 71-89.

Kozlenkova, Irina V., Robert W. Palmatier, Eric (Er) Fang, Bangming Xiao, and Minxue Huang (2017), "Online Relationship Formation,” Journal of Marketing, 81 (3), 21-40.

Lancastre, Andrew, and Luis Filipe Lages (2006), "The Relationship Between Buyer and a B2B E-Marketplace: Cooperation Determinants in an Electronic Market Context," Industrial Marketing Management, 35 (6), 774-89.

Leeflang, Peter S.H., Peter C. Verhoef, Peter Dahlström, and Tjark Freundt (2014), "Challenges and Solutions for Marketing in a Digital Era," European Management Journal 32 (1), 1-12.

Leonidou, Leonidas C., Bilge Aykol, Thomas A. Fotiadis, Paul Christodoulides, and Athina Zeriti (2017), "Betrayal in International Buyer-Seller Relationships: Its Drivers and Performance Implications," Journal of World Business, 52 (1), $28-44$.

Leonidou, Leonidas C., Saeed Samiee, Bilge Aykol, and Michael A. Talias (2014), "Antecedents and Outcomes of ExporterImporter Relationship Quality: Synthesis, Meta-Analysis, and Directions for Further Research," Journal of International Marketing, 22 (2), 21-46.

Lusch, Robert F., and James R. Brown (1996), "Interdependency, Contracting, and Relational Behavior in Marketing Channels," Journal of Marketing, 60 (4), 19-38.

Mahdjoubi, Lamine, Jing Hao Koh, and Cletus Moobela (2014), "Effects of Interactive Real-Time Simulations and Humanoid Avatars on Consumers' Responses in Online House Products Marketing," Computer-Aided Civil and Infrastructure Engineering, 29 (1), 31-46.

Manyika, James, Jacques Bughin, Jonathan Woetzel, Kalin Stamenov, and Dhruv Dhingra (2016), "Digital Globalization: The New Era of Global Flows," McKinsey Global Institute, http://www.mckinsey.com/business-functions/digital-mckinsey/ our-insights/digital-globalization-the-new-era-of-global-flows.

Marketing Science Institute (2016), "Research Priorities 2016-2018," http://www.msi.org/uploads/articles/MSI_RP16-18.pdf.

Martin, Kelly D., Abhishek Borah, and Robert W. Palmatier (2017), "Data Privacy: Effects on Customer and Firm Performance," Journal of Marketing, 81 (1), 36-58.

Martínez-López, Francisco J., and Jorge Casillas (2013), "Artificial Intelligence-Based Systems Applied in Industrial Marketing: An Historical Overview, Current and Future
Insights," Industrial Marketing Management, 42 (4), 489-95.

Mathews, Shane, Constanza Bianchi, Keith J. Perks, Marilyn Healy, and Rumintha Wickramasekera (2016), "Internet Marketing Capabilities and International Market Growth," International Business Review, 25 (4), 820-30.

McCole, Patrick (2002), "The Role of Trust for Electronic Commerce in Services," International Journal of Contemporary Hospitality Management, 14 (2), 81-87.

Mela, Carl F., Jason Roos, and Yiting Deng (2013), “A Keyword History of Marketing Science,” Marketing Science, 32 (1), 8-18.

Möller, Kristian, and Aino Halinen (2000), "Relationship Marketing Theory: Its Roots and Direction," Journal of Marketing Management, 16 (1/3), 29-54.

Moorman, Christine, Gerald Zaltman, and Rohit Deshpandé (1992), "Relationships Between Providers and Users of Market Research: The Dynamics of Trust Within and Between Organizations," Journal of Marketing Research, 29 (August), 314-28.

Morgan, Robert M., and Shelby D. Hunt (1994), "The Commitment-Trust Theory of Relationship Marketing," Journal of Marketing, 58 (3), 20-38.

Morgan-Thomas, Anna, and Cleopatra Veloutsou (2013), "Beyond Technology Acceptance: Brand Relationships and Online Brand Experience," Journal of Business Research, 66 (1), 21-27.

Namiki, Nobuaki (1994), “A Taxonomic Analysis of Export Marketing Strategy: An Exploratory Study of U.S. Exporters of Electronic Products," Journal of Global Marketing, 8 (1), $27-50$.

Nee, Victor, Sonja Opper, and Sonia Wong (2007), "Developmental State and Corporate Governance in China," Management and Organization Review, 3 (1), 19-53.

Oxley, Joanne E., and Bernard Yeung (2001), "E-Commerce Readiness: Institutional Environment and International Competitiveness," Journal of International Business Studies, 32 (4), 705-24.

Pagani, Margherita (2013), "Digital Business Strategy and Value Creation: Framing the Dynamic Cycle of Control Points," Management Information Systems Quarterly, 37 (2), 617-32.

Palmatier, Robert W., Rajiv P. Dant, and Dhruv Grewal (2007), "A Comparative Longitudinal Analysis of Theoretical Perspectives of Interorganizational Relationship Performance," Journal of Marketing, 71 (4), 172-94. 
Palmatier, Robert W., Rajiv P. Dant, Dhruv Grewal, and Kenneth R. Evans (2006), "Factors Influencing the Effectiveness of Relationship Marketing: A Meta-Analysis," Journal of Marketing, 70 (4), 136-53.

Pardo, Catherine, Björn S. Ivens, and Kevin Wilson (2013), "Assessing and Strengthening Internal Alignment of New Marketing Units: An Interpretative Tool," Industrial Marketing Management, 42 (2), 1074-82.

Pavlou, Paul A., H. Liang, and Y. Xue (2007), “Understanding and Mitigating Uncertainty in Online Exchange Relationships: A Principle-Agent Perspective," Management Information Systems Quarterly, 31 (1), 105-36.

Pazgal, Amit, and David Soberman (2008), "Behavior-Based Discrimination: Is It a Winning Play, and If So, When?" Marketing Science, 27 (6), 977-94.

Petersen, Bent, Lawrence S. Welch, and Peter W. Liesch (2002), "The Internet and Foreign Market Expansion by Firms," Management International Review, 42 (2), 207-21.

Poppo, Laura, and Todd Zenger (2002), “Do Formal Contracts and Relational Governance Function as Substitutes or Complements?” Strategic Management Journal, 23(8), 707-25.

Porter, Michael E. (1980), Competitive Strategy. New York: The Free Press.

Poulter, Julian (2016), "Market Share Analysis: Customer Relationship Management Software, Worldwide 2015," Gartner Research, http://www.gartner.com/document/ 3315925 ? ref $=$ solrAll $\&$ refval $=168053828 \&$ qid $=4 a 3293 \mathrm{e} 84 \mathrm{~d} 8 \mathrm{fe}$ $735029658 \mathrm{a} 9 \mathrm{c} 358 \mathrm{f} 3 \mathrm{~b} 8$.

Ray, Gautam, Jay B. Barney, and Waleed A. Muhanna (2004), "Capabilities, Business Processes, and Competitive Advantage: Choosing the Dependent Variable in Empirical Tests of the Resource-Based View," Strategic Management Journal, 25 (1), 23-37.

Reinmoeller, Patrick, and Shaz Ansari (2016), “The Persistence of a Stigmatized Practice: A Study of Competitive Intelligence," British Journal of Management, 27 (1), 116-42.

Rothaermel, Frank T., Suresh Kotha, and Kevin Steensma (2006), “International Market Entry by U.S. Internet Firms: An Empirical Analysis of Country Risk, National Culture, and Market Size," Journal of Management, 32 (1), 56-82.

Saadi, Malik (2017), "Handsets \& Devices," ABI Research, London, England. Accessed on March 15, 2017, https://www. abiresearch.com/market-research/service/handsets-devices/

Samaha, Stephen A., Joshua T. Beck, and Robert W. Palmatier (2014), "The Role of Culture in International Relationship Marketing," Journal of Marketing, 78 (5), 78-98.
Samiee, Saeed, and Brian R. Chabowski (2012), "Knowledge Structure in International Marketing: A Multi-Method Bibliometric Analysis," Journal of the Academy of Marketing Science, 40 (2), 364-86.

Samiee, Saeed, Brian R. Chabowski, and G. Tomas M. Hult (2015), "International Relationship Marketing: Intellectual Foundations and Avenues for Further Research," Journal of International Marketing, 23 (4), 1-21.

Schu, Matthias, and Dirk Morschett (2017), "Foreign Market Selection of Online Retailers: A Path-Dependent Perspective on Influence Factors," International Business Review, 26 (3), 710-23.

Sen, Ravi, and Sharad Borle (2015), "Estimating the Contextual Risk of Data Breach: An Empirical Approach," Journal of Management Information Systems, 32 (2), 314-41.

Seshadri, Sudhi, and Randhir Mishra (2004), "Relationship Marketing and Contract Theory," Industrial Marketing Management, 33 (6), 513-26.

Sheng, Shibin, Kevin Zheng Zhou, and Julie Juan Li (2011), “The Effects of Business and Political Ties on Firm Performance: Evidence from China," Journal of Marketing, 75 (1), 1-15.

Simmons, Geoff (2008), "Marketing to Postmodern Consumers: Introducing the Internet Chameleon," European Journal of Marketing, 42 (3/4), 299-310.

Skarmeas, Dionisis, Constantine S. Katsikeas, and Bodo B. Schlegelmilch (2002), "Drivers of Commitment and Its Impact on Performance in Cross-Cultural Buyer-Seller Relationship: The Importer's Perspective," Journal of International Business Studies, 33 (4), 757-83.

Skarmeas, Dionysis, Athina Zeriti, and George Baltas (2016), "Relationship Value: Drivers and Outcomes in International Marketing Channels," Journal of International Marketing, 24 (1), 22-40.

Song, Peijian, Cheng Zhang, Yunjie Calvin $\mathrm{Xu}$, and Lihua Huang (2010), "Brand Extension of Online Technology Products: Evidence from Search Engine to Virtual Communities and Online News,” Decision Support Systems, 49 (1), 91-99.

Sousa, Carlos M.P., and Frank Bradley (2006), "Cultural Distance and Psychic Distance: Two Peas in a Pod?" Journal of International Marketing, 14 (1), 49-70.

Srinivasan, Raji, and Christine Moorman (2005), "Strategic Firm Commitments and Rewards for Customer Relationship Management in Online Retailing," Journal of Marketing, 69 (4), 193-200.

Sultan, Fareena, Andrew J. Rohm, and Tao Tony Gao (2009), "Factors Influencing Consumer Acceptance of Mobile 
Marketing: A Two-Country Study of Youth Markets," Journal of Interactive Marketing, 23 (4), 308-20.

Sun, Baohong (2006), "Technology, Innovation, and Implications for Customer Relationship Management," Marketing Science, 25 (6), 594-97.

Swant, Marty (2016), "Facebook and Amazon Seem to Be Increasingly Concerned About Your Data," Adweek (February 24), http://www.adweek.com/digital/facebook-and-amazon-seem-beincreasingly-concerned-about-your-data-169834/.

Teece, David J (1986), “Transactions Cost Economics and the Multinational Enterprise An Assessment," Journal of Economic Behavior \& Organization, 7 (1), 21-45.

Tellis, Gerard J., Rajesh K. Chandy, and David S. Ackerman (1999), "In Search of Diversity: The Record of Major Marketing Journals," Journal of Marketing Research, 36 (1) $120-31$.

Theodosiou, Marios, and Constantine S. Katsikeas (2001), "Factors Influencing the Degree of International Pricing Strategy Standardization of Multinational Corporations," Journal of International Marketing, 9 (3), 1-18.

Thomson Reuters (2009), Web of Science 8.0. New York: Thomson Reuters.

Tiago, Maria Teresa Pinheiro Melo Borges, and Jose Manuel Cristovao Verissimo (2014), "Digital Marketing and Social Media: Why Bother?” Business Horizons, 57 (6), 703-08.

Tucker, Catherine (2014), "Social Networks, Personalized Advertising, and Privacy Controls," Journal of Marketing Research, 51 (October), 546-62.

Uddin, Moshfique, and Agyenim Boateng (2011), "Explaining the Trends in the UK Cross-Border Mergers and Acquisitions: An Analysis of Macro-Economic Factors," International Business Review, 20 (2), 547-56.

Varadarajan, P. Rajan, and Manjit S. Yadav (2002), "Marketing Strategy and the Internet: An Organizing Framework," Journal of the Academy of Marketing Science, 30 (4), 296-312.

Verma, Varsha, Dheeraj Sharma, and Jagdish Sheth (2016), "Does Relationship Marketing Matter in Online Retailing? A Meta-Analytic Approach," Journal of the Academy of Marketing Science, 44 (2), 206-17.

Vernon, Raymond (1966), "International Investment and International Trade in the Product Cycle," Quarterly Journal of Economics, 80 (2), 190-207.

Voldnes, Goril, Kjell Gronhaug, and Frode Nilssen (2012), "Satisfaction in Buyer-Seller Relationships: Influence of Cultural Differences," Industrial Marketing Management, 41 (7), 1081-93.
Wang, Cheng Lu (2007), “Guanxi vs. Relationship Marketing: Exploring Underlying Differences," Industrial Marketing Management, 36 (1), 81-86.

Wang, William Y.C., David J. Pauleen, and Tingting Zhang (2016), "How Social Media Applications Affect B2B Communication and Improve Business Performance in SMEs," Industrial Marketing Management, 54, 4-14.

Watson, George F., IV, Joshua T. Beck, Conor M. Henderson, and Robert W. Palmatier (2015a), "Building, Measuring, and Profiting from Customer Loyalty," Journal of the Academy of Marketing Science, 43 (6), 790-825.

Watson, George F., IV, Stefan Worm, Robert W. Palmatier, and Shankar Ganesan (2015b), "The Evolution of Marketing Channels: Trends and Research Directions," Journal of Retailing, 91 (4), 546-68.

Weinberg, Bruce D., Lenita Davis, and Paul D. Berger (2013), "Perspectives on Big Data," Journal of Marketing Analytics, 1 (4), 187-201.

Williamson, Oliver E. (1985), The Economic Institutions of Capitalism. New York: The Free Press.

Wind, Yoram, Susan P. Douglas, and Howard V. Perlmutter (1973), "Guidelines for Developing International Marketing Strategies," Journal of Marketing, 37 (2), 12-23.

Wu, Aiqi, and Lianxi Zhou (2017), "Understanding Earliness of Internationalization and Its Impact on Post-Entry Geographic Diversity of International Young Ventures," Journal of International Marketing, forthcoming (published electronically October 27), DOI: 10.1509/jim.16.0123.

Yadav, Manjit S., and Paul A. Pavlou (2014), "Marketing in Computer-Mediated Environments: Research Synthesis and New Directions," Journal of Marketing, 78 (January), 20-40.

Yang, Zhilin, Chenting Su, and Kim-Shyan Fam (2012), "Dealing with Institutional Distances in International Marketing Channels: Governance Strategies that Engender Legitimacy and Efficiency," Journal of Marketing, 76 (3), 41-55.

Zeithaml, Valarie A., Roland T. Rust, and Katherine N. Lemon (2001), "The Customer Pyramid: Creating and Serving Profitable Customers," California Management Review, 43 (4), 118-42.

Zhang, Jonathan Z., George F. Watson IV, Robert W. Palmatier, and Rajiv P. Dant (2016), "Dynamic Relationship Marketing," Journal of Marketing, 80 (September), 53-75.

Zhuang, Guijun, and Xubing Zhang (2011), "Impact of Relationship Marketing Orientation on the Exercise of Interfirm Power and Relational Governance in Marketing Channels: Empirical Evidence from China," Journal of Marketing Channels, 18 (4), 279-302. 